\title{
Geoquímica del magmatismo mesozoico asociado al Margen Continental Pasivo en el occidente y centro de Cuba
}

\author{
Esther María Gruz-Gámez, Fernando Velasco-Tapia, Antonio García-Casco, \\ Ana Ibis Despaigne Díaz, José Francisco Lastra Rivero, Damaso Gáceres Govea
}

Esther María Gruz-Gámez

esther.cruzgm@uanl.edu.mx

Universidad Autónoma de Nuevo León, Facultad de Ciencias de la Tierra, Ex-Hacienda de Guadalupe, Carretera Linares-Cerro Prieto km 8, C.P. 67700 ,

Linares, N.L., México.

Universidad de Pinar del Río, Facultad de Ciencias Técnicas, Martí 270, 20100, Pinar del Río, Cuba.

\section{Fernando Velasco-Tapia}

Universidad Autónoma de Nuevo León, Facultad de Ciencias de la Tierra, Ex-Hacienda de Guadalupe, Carretera Linares-Cerro Prieto km 8, C.P. 67700 , Linares, N.L., México.

\section{Antonio García-Casco}

Universidad de Granada, Departamento de

Mineralogía y Petrología, Instituto Andaluz de

Ciencias de la Tierra (UGR-CSIC), Avenida

Fuentenueva s/n, 18079, Granada, España.

\section{Ana Ibis Despaigne Díaz}

Universidad de Pinar del Río, Facultad de Ciencias Técnicas, Martí 270, 20100, Pinar del Río, Cuba.

\section{José Francisco Lastra Rivero}

Universidad de Pinar del Río, Facultad de Ciencias Técnicas, Martí 270, 20100, Pinar del Río, Cuba.

\section{Damaso Cáceres Govea}

Universidad de Pinar del Río, Facultad de Ciencias Técnicas, Martí 270, 20100, Pinar del Río, Cuba.

BOL. SOC. GEOL. MEX. 2016

VOL. 68 NO. 3

P. $443-475$

Manuscrito recibido: Octubre 6, 2015 Manuscrito corregido: Marzo 29, 2016 Manuscrito aceptado: Abril 1, 2016

\section{RESUMEN}

Secuencias estratigráficas de Margen Continental Pasivo (MCP) han sido descritas en la región mesoamericana. En Cuba las mismas están representadas por rocas siliciclásticas y carbonatadas Litologías de origen magmático (hialoclastita, basalto, diabasa y gabro) y meta-magmático (metavolcánicos, metagabro, anfibolita y eclogita) entre otras, aparecen intercaladas en los cortes sedimentarios. Esta actividad magmática se ha relacionado con la fragmentación de Pangea (en un proceso de tipo rift-drift) y con la etapa inicial de desarrollo de la corteza oceánica del proto-Caribe. A partir de la interpretación de una amplia base de datos petrográficos y geoquímicos (considerando información publicada, así como generada en el presente estudio), se propone un modelo conceptual para explicar el magmatismo del MCP que aflora en la Cordillera Guaniguanico y los terrenos metamórficos de Pinos y Escambray: (a) posiblemente durante el Jurásico Inferior (?) - Jurásico Superior (Oxfordiano Medio/Superior) en un ambiente de Margen Continental, se produjo un magmatismo tipo E-MORB por fusión parcial de una fuente mantélica enriquecida; (b) un volumen importante de magma tipo N-MORB fue generado (producto de una fusión parcial de una fuente mantélica empobrecida) cuando la apertura del océano fue suficiente para que se estableciera una dispersión en estado estacionario, sin la influencia de sistemas de pluma mantélica. Este magmatismo alcanzó su máxima generación en el Oxfordiano Superior Kimmeridgiano temprano?; (c) cuando se produjo el magma de características N-MORB, es probable que además se alojará (en forma de sills y diques) en las secuencias anteriormente formadas en el estadío syn-rift del margen continental. Por lo que es posible encontrar litologías de este tipo en secuencias más antiguas a dicho evento (e.g., formaciones Loma La Gloria y Arroyo Cangre); y (d) durante el Cretácico Inferior tardío al Cretácico Superior basal se registró un magmatismo de tipo E-MORB (e.g., formaciones Yaguanabo y El Tambor), el cual estuvo posiblemente relacionado con una nueva condición de margen vinculado a Caribeana. La mayor parte de las litologías magmáticas y sedimentarias del MCP fueron metamorfizadas en la subducción del Caribe durante el Campaniano Superior tardío y, posteriormente, exhumadas en el periodo Maastrichtiano - Paleoceno temprano.

Palabras clave: Guba, magmatismo Mesozoico, Margen Continental Pasivo, MORB.

\section{ABSTRACT}

Jurassic to Cretaceous stratigraphic sequences of Passive Continental Margin (PCM) have been described in several localities of the Mesoamerican region. In Cuba these rocks are widely exposed, being constituted by carbonate and siliciclastic rocks. Magmatic (hyaloclastite, basalt, diabase, and gabbro) and meta-magmatic (metavolcanics, metagabbro, amphibolite, and eclogite) lithologies occur intercalated within these geological sequences. This magmatic activity has been related to the fragmentation of Pangea (in a rift-drift process) and the initial development of the proto-Caribbean oceanic basin. In this work, based on the interpretation of an extensive petrographic and geochemical database (considering published information as well as data generated during this study), a conceptual model is proposed for the PCM magmatism distributed along the Guaniguanico Cordillera and the Pinos and Escambray metamorphic terranes: (a) in a Continental Margin Ridge setting, probably during the Lower Furassic (?) to Upper Jurassic (Middle/Upper Oxfordian), E-MORB-type magmatism was produced from an enriched mantle; (b) $\mathcal{N}$-MORB-type magma was erupted (produced by partial melting of a depleted mantle) when the ocean opened sufficiently for steady-state spreading to be established, without the influence of a plume system. This magmatism peaked in the Upper Oxfordian - Early Kimmerigdian?; (c) sills and dykes of $\mathcal{N}$-MORB-type magmas also intruded syn-rift sedimentary sequences, explaining the occurrence of this type of magmatism in the earliest deposited sequences of the passive margin (e.g., Loma La Gloria and Arroyo Cangre formations); and (d) E-MORB-type magmatism occurred during late Lower Cretaceous to basal Upper Cretaceous (e.g., Yaguanabo and El Tambor formations), probably linked to the Caribbean margin. The majority of magmatic and sedimentary PMC lithologies were metamorphosed during the Upper Campanian and afterward exhumed in the Maastrichtian - Early Paleocene period.

Keywords: Cuba, Mesozoic Magmatism, Continental Pasive Margin, MORB. 


\section{Introducción}

En diversas regiones de Guba afloran secuencias de Margen Continental Pasivo (MCP) del Jurásico al Cretácico, las cuales forman parte del denominado Cinturón Plegado Cubano (Piotrowski, 1987; Iturralde-Vinent, 1998; Cobiella-Reguera, 2000). Estas secuencias están expuestas en la Cordillera de Guaniguanico; Terrenos Pinos, Escambray y Asunción (Figura 1) y, presentan semejanzas en su estratigrafía (Somin y Millán, 1977; Stanik et al., 1981; Millán, 1981, 1992, 1997a-c; Pszczolkowski, 1987, 1999; Millán y Somin, 1985a,b; Dublan et al., 1986; Martínez y Fernández de Lara, 1988; Iturralde-Vinent, 1994, 1998; Cobiella-Reguera y Olóriz, 2009). En general, se inician en su base con depósitos siliciclásticos del Jurásico Inferior? - Jurásico Superior que transicionan a estratos de carbonatos y, en algunos casos, a secuencias carbonato-terrígenas a partir del Jurásico Superior (parte baja). Por otra parte, algunos rasgos paleon- tológicos comunes soportan además su correlación cronológica (e.g., amonites oxfordianos en la base de los carbonatos de Guaniguanico y Escambray; Millán y Myczyñski, 1979; Millán y Somin, 1985b).

Haczewski (1976) señaló que la Formación San Cayetano (la más antigua en la Cordillera de Guaniguanico) puede ser considerada como un depósito transicional de los estadios del rift-drift (terrestres, aluviales, lagunares y marinos someros) en una condición de ruptura continental. Posteriormente, Hutson et al. (1998) indicaron que la parte superior de las secuencias de esta misma formación representan depósitos deltáicos de postrift. Pszczolkowski (1999) señaló que las unidades de Guaniguanico correspondientes al Jurásico Inferior- Calloviano?/Oxfordiano Inferior son del estadío de syn-rift y las de edad Calloviano?/ Oxfordiano Medio- Santoniano de drift.

Estas sucesiones de MCP también incluyen litologías magmáticas en el intervalo Jurásico Inferior?

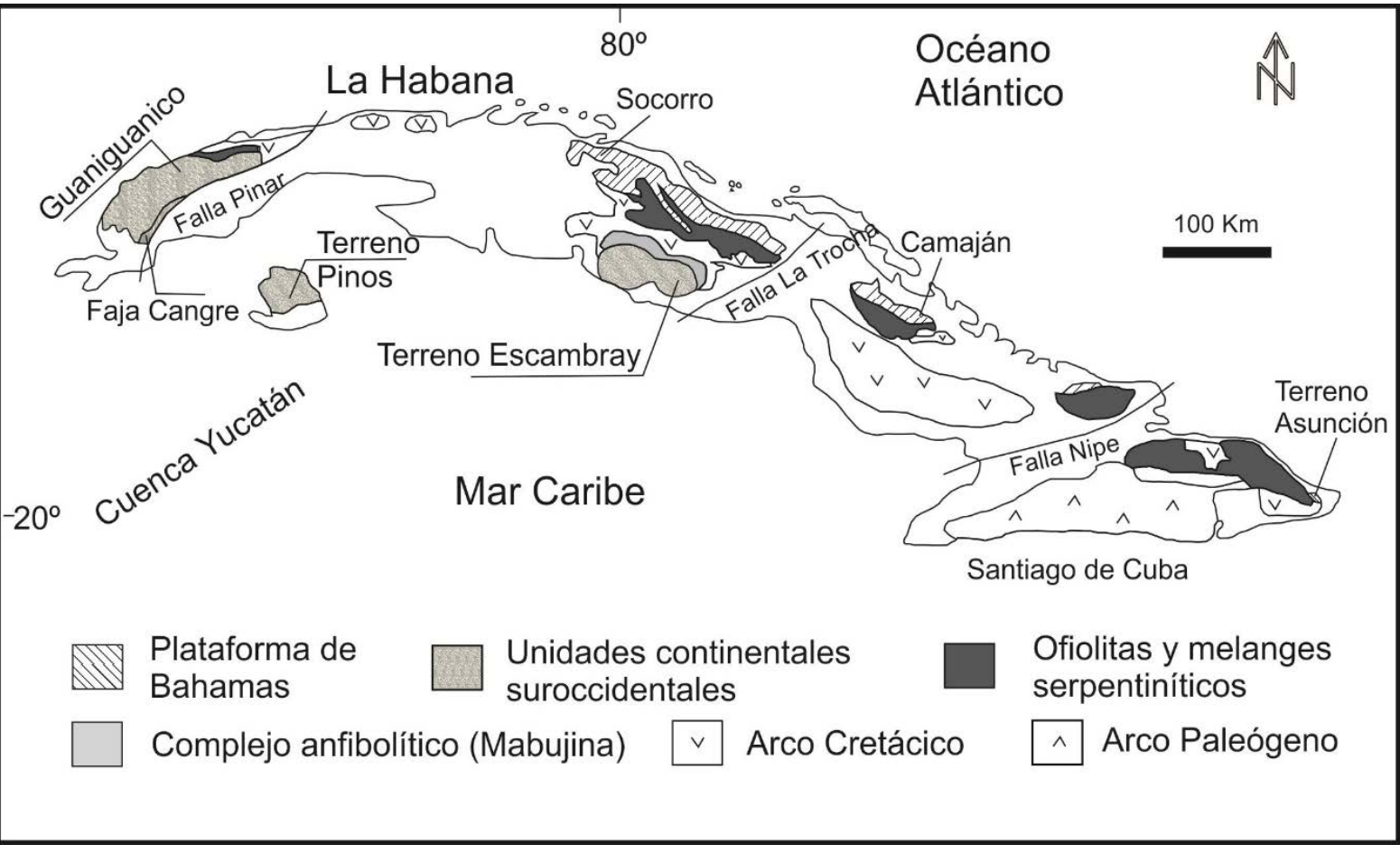

Figura 1 Ubicación de las unidades continentales que conforman el Margen Continental Pasivo en el occidente y centro de Cuba (Cordillera de Guaniguanico, Terreno Pinos, Terreno Escambray, Sierra de Camaján y Terreno Asunción) y otros complejos geológicos de importancia (modificado de Iturralde-Vinent, 1996). 
- Cretácico Superior (parte baja)? Estas rocas, interpretadas como magmatismo de margen continental (Iturralde-Vinent, 1988b, 1996), incluyen: (a) hialoclastita, basalto, diabasa, dolerita, gabro, metagabro y metabasalto en la Cordillera de Guaniguanico (CG; Pszczolkowski y Albear, 1983; Segura-Soto et al., 1985; Piotrowski, 1987; Iturralde-Vinent, 1988a,b, 1996; Pszczolkowski, 1989; Cobiella-Reguera, 1996; Linares, 1997; Kerr et al., 1999; Allibon et al., 2008); (b) anfibolitas en el Terreno Pinos (TP; Millán, 1975, 1981, 1997b; Iturralde-Vinent, 1988a, 1996); (c) metavolcánicos, metabasitas en facies de esquisto verde, esquisto azul y eclogita en el Terreno Escambray (TE; Stanik et al., 1981; Millán y Somin, 1985a,b; Dublan et al., 1986; Iturralde-Vinent, 1988a,b, 1996; Millán, 1997b; Álvarez-Sánchez et al., 1991; Linares, 1997); (d) hialoclastita y basalto en la Sierra de Camaján (Iturralde-Vinent y Marí, 1988); y (e) metavulcanitas básicas en el Terreno Asunción, Cuba Oriental (Iturralde-Vinent, 1988a). Estas litologías, intercaladas con las secuencias siliciclásticas y carbonatadas, representan la actividad magmática más antigua conocida en las rocas cubanas, junto a los granitos de edad Jurásico Medio ubicados en la localidad Socorro (Figura 1).

Teniendo en cuenta la evolución geotectónica de América Central, el Golfo de México y el Caribe, existen diversas hipótesis respecto a la ubicación paleogeográfica de estas secuencias. Iturralde-Vinent (1994) atribuyó el término "terreno tectonoestratigráfico” a Guaniguanico, Pinos y Escambray, considerándolos como fragmentos del bloque Maya, desplazados hacia su posición actual luego de la fragmentación de Pangea (iniciada en Jurásico Inferior?) y la formación de una cuenca intracontinental (e.g., San Cayetano; Rojas-Agramonte et al., 2008) precursora del "Tethys Americano". Hutson et al. (1998), a partir de petrografía y edades ${ }^{40} \mathrm{Ar}-{ }^{39} \mathrm{Ar}$ en micas clásticas, establecieron la fuente de la Formación San Cayetano en Belice, al extremo suroriental del bloque Maya. En este sentido, Rojas-Agramonte et al. (2008), a partir del estudio de circones detríticos, señalaron que sus principales fuentes de aporte fueron los bloques de América del Sur y Yucatán. También Pszczolkowski (1999) sugirió una relación entre Guaniguanico con el bloque Maya y Suramericano. Por otra parte, García-Casco et al. (2008) definieron el dominio paleogeográfico "Caribeana" como un mega-terreno caracterizado por pilas sedimentarias mesozoicas depositadas en el contexto del proto-Caribe que fueron metamorfizadas, en una zona de subducción durante el Campaniano Superior, a diferencia de los márgenes continentales no subducidos del bloque Maya (Guaniguanico) y margen de Bahamas. El terreno Caribeana fue exhumado, fragmentado y dispersado a lo largo del límite septentrional de la placa del Caribe durante el Cretácico tardío - Paleógeno. Estos autores sugirieron además que las unidades tectónicas metamorfizadas de la Cordillera de Guaniguanico (Faja Cangre) y los terrenos Pinos, Escambray y Asunción formaron parte de Caribeana.

Allibon et al. (2008) indicaron que el magmatismo presente en la Formación El Sábalo (Jurásico Superior - Oxfordiano/Kimmerigiano temprano?; según Pszczolkowski, 1999) ocurrió durante la separación del bloque Maya y América del Sur. Aunque existen diversos reportes sobre este magmatismo de Margen Continental y sus equivalentes metamorfizados en las secciones del mesozoico cubano (Piotrowski, 1977, 1987; Pszczolkowski y Albear, 1983; Segura-Soto et al., 1985; Dublan et al., 1986; Piotrowski, 1987; Iturralde-Vinent, 1988a,b, 1996; Pszczolkowski, 1989; Cobiella-Reguera, 1996; Linares, 1997; Kerr et al., 1999; Schneider et al., 2004; Allibon et al., 2008; Iturralde-Vinent, 2012), la información petrográfica y geoquímica aún es limitada para algunas localidades y, en otros casos aunque ha sido analizada integralmente (e.g., Iturralde-Vinent, 1988b, 1996), los datos geoquímicos existentes son escasos y, en general, sólo se utilizan elementos mayores.

En el presente estudio se reporta nueva información petrográfica y geoquímica (20 muestras) para rocas magmáticas y meta-magmáticas de la Cordillera de Guaniguanico y los terrenos Pinos y Escambray (Figura 2 A-C), y se caracteriza su relación espacio-temporal. A partir de esta in- 
formación y la documentada de forma previa se propone un modelo conceptual en el contexto de formación del margen pasivo Norteamericano durante el Jurásico-Cretácico.

\section{Estratigrafía del MCP en el occidente y centro de Cuba}

En la Figura 3 se presenta un esquema general de los cortes estratigráficos estudiados en el MCP del occidente y centro de Cuba con indicación de las intercalaciones magmáticas y metamagmáticas, los cuales cubren desde el Triásico tardío? al Cretácico Superior. Este esquema se basa en trabajos de campo llevados a cabo por los autores y los reportes disponibles en la literatura (e.g. Kantchev et al., 1978; Dublan et al., 1986; Pszczolkowski, 1987, 1999; Millán, 1997c; Furrazola-Bermúdez, 1997; Pszczolkowski y Myczynski, 2003; Stanek et al., 2006; Iturralde-Vinent, 2012). A continuación se presenta una breve descripción, en dirección Oeste a Este, de las unidades tectono-estratigráficas presentes a lo largo del MCP (Figura 1).

La Cordillera de Guaniguanico (Figuras 2A y 3) está constituida por un apilamiento de mantos de sobrecorrimiento que se desarrolló durante el Paleoceno-Eoceno Medio (Piotrowski, 1987; Bralower e Iturralde-Vinent, 1997). De acuerdo a la posición geográfica y a la secuencia de litologías, se han identificado las siguientes unidades tectono-estratigráficas: Faja Cangre, Los Órganos, Rosario Sur, Rosario Norte y Quiñones-Guajaibón (Iturralde-Vinent, 1998; Pszczolkowski, 1999; Figura 2A). Las secciones estratigráficas se inician con sedimentos siliciclásticos de las formaciones San Cayetano y Arroyo Cangre (Pszczolkowski, 1999, Figura 3). Éstos son cubiertos por rocas marinas calcáreas con intercalaciones de estratos siliciclásticos, correspondientes a las formaciones Jagua, Francisco, Guasasa (parte baja), Artemisa (parte baja) y El Sábalo, y por rocas marinas calcáreas y silíceas de agua más profunda, representadas por las formaciones Guasasa (parte alta), Artemisa (parte alta), Polier, Lucas, Pons, Santa Teresa, Car- mita, Pinalilla, Peñas y Moreno (Figura 3). Se ha reportado que las unidades Faja Cangre, Rosario Norte y Sur incluyen rocas ígneas (Tabla 1). Sin embargo, sólo en Faja Cangre existe evidencia de metamorfismo de baja T y alta P (Millán, 1972; Cruz-Gámez et al., 2007), ubicado en el Cretácico Superior (parte alta) (García-Casco et al., 2008).

El Terreno Pinos (Figuras 2B y 3) está representado por secciones estratigráficas de rocas meta-siliciclásticas y meta-carbonatadas, agrupadas en las formaciones Cañada, Agua Santa y Grupo Gerona (Figura 3). García-Casco et al. (2001) reportaron un metamorfismo en condiciones de grado bajo a alto, con un pico a $750^{\circ} \mathrm{C}$ y 11-12 kbar para rocas migmatíticas. Las secuencias están deformadas y plegadas (Eguipko et al., 1975; Babushkin, 1990; Millán, 1997b) y subyacen tectónicamente a rocas no metamorfizadas del Arco Volcánico Cretácico (Formación Sabana Grande, Figura 2B). Dentro de los cortes del MCP en el Terreno Pinos se han reportado las anfibolitas en Daguilla y en la Formación Sierra de Caballos del Grupo Gerona (Tabla 2; Figura 3).

En el Terreno Escambray (Figuras 2C y 3), los cortes estratigráficos del Jurásico Inferior al Cretácico Superior muestran similitud estratigráfica con los reportados para la Cordillera de Guaniguanico y el Terreno Pinos (Millán y Somin 1985b; Dublan et al., 1986; Millán 1997a-c; Figura 3). Las secuencias originales se encuentran transformadas por el metamorfismo y la tectónica. El terreno cuenta con cuatro unidades tectónicas mayores que, aunque comparten algunas formaciones estratigráficas, muestran condiciones metamórficas distintas (Figura 3; e.g., Stanik et al., 1981; Dublan et al., 1986; Millán, 1995, 1997a-c, Despaigne-Díaz, 2009, y referencias allí contenidas). Además, debido a la complejidad tectónica del terreno, no existe información precisa de los espesores de algunas de estas formaciones. La unidad I incluye las siguientes formaciones: Llamagua (siliciclástica), Grupo San Juan (carbonatada), Los Cedros (carbonatada-silícea; Stanik et al., 1981, reportaron microfauna del Tithoniano-Cretácico Inferior en unos sedimentos que posteriormente fueron atribuidos a esta For- 

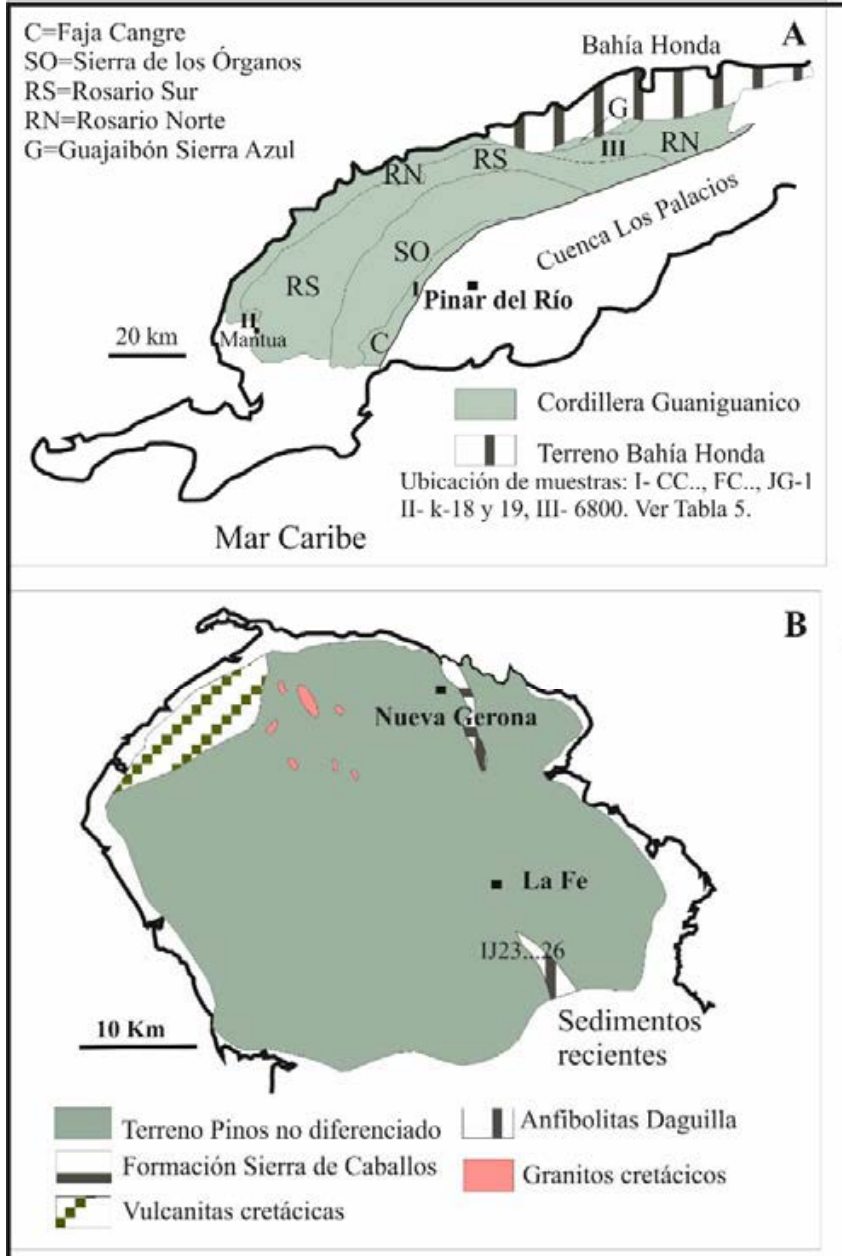

B
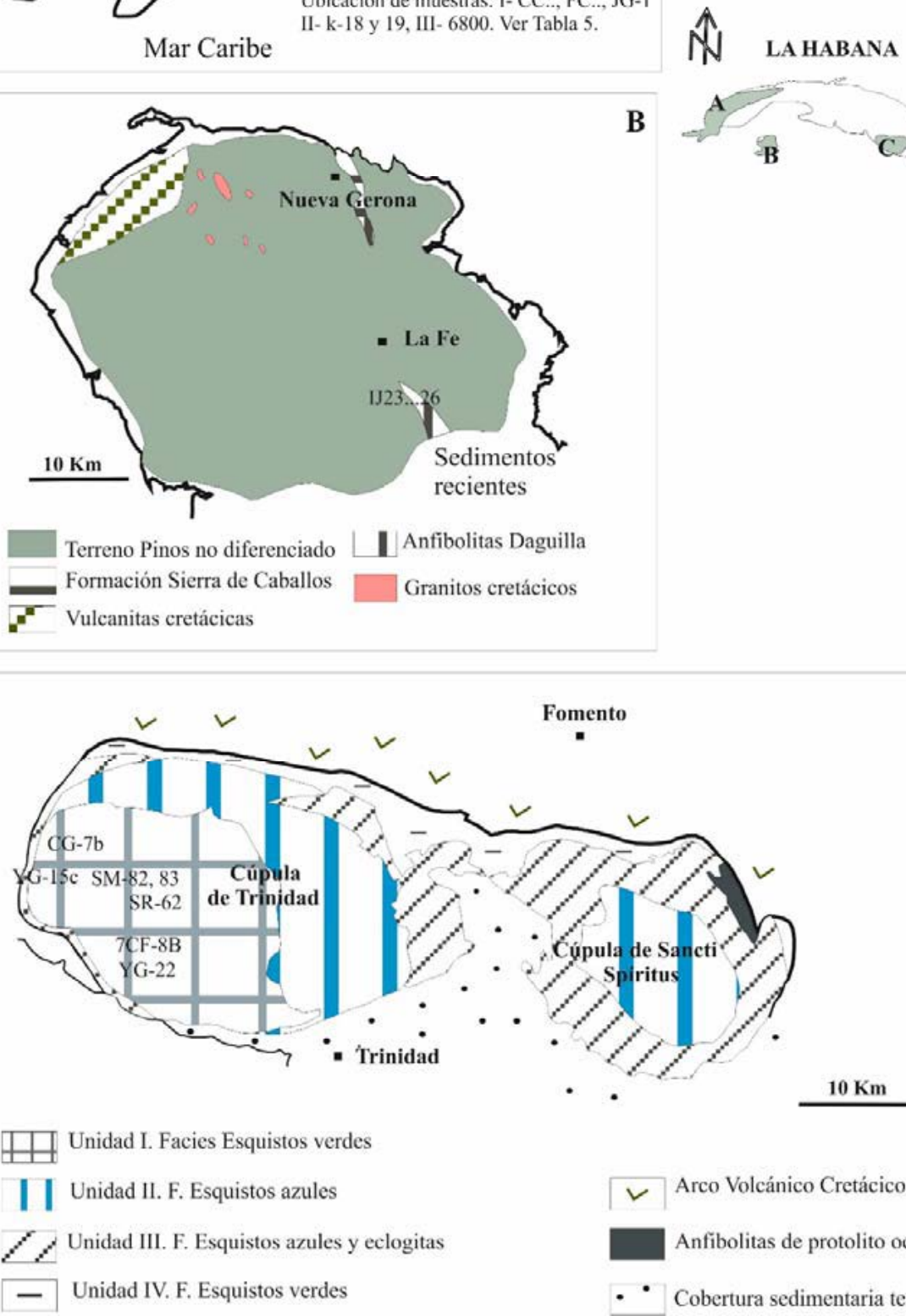

Fomento

Distribución de rocas magmáticas y meta-magmáticas del tipo Margen Continental Pasivo en el occidente y centro de Cuba: (A) Cordillera de Guaniguanico (Pszczolkowski, 1999); (B) Terreno Pinos - Isla de la Juventud (Millán, 1997b); (C) Terreno Escambray (Millán, 1997c). Se indica la localización de las muestras reportadas en las Tablas 5-7. 


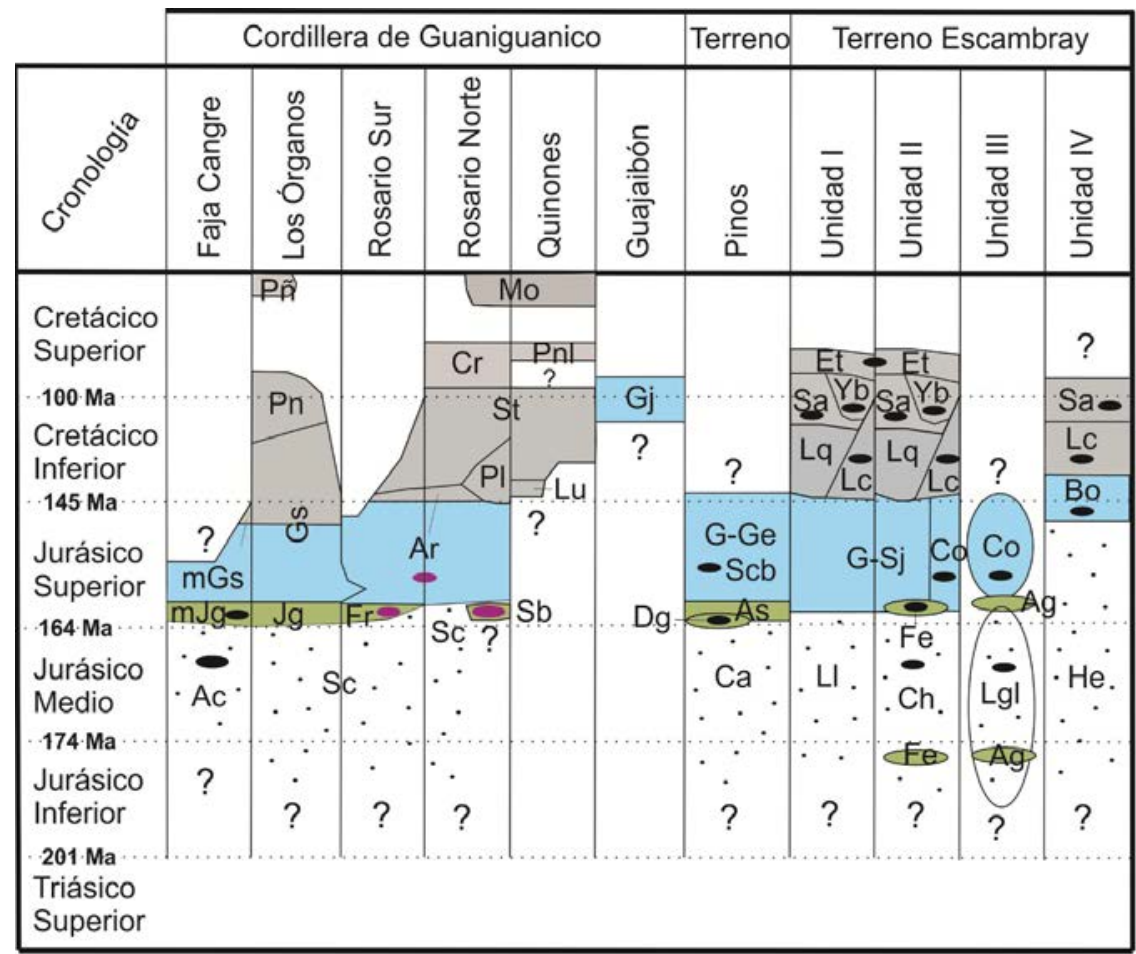

\footnotetext{
$\square$ Rocas detriticas continentales $\square$ Rocas detriticas y marinas $\quad$ Mafitas no metamorfizadas

$\square$ Rocas de aguas poco profundas $\square$ Rocas de aguas profundas $\bullet$ Mafitas metamorfizadas
}

Figura 3 Columnas estratigráficas generalizadas para las secuencias mesozoicas (Jurásico Inferior - Cretácico Inferior) de Margen Continental Pasivo en el occidente y centro de Cuba (basadas en: Kantchev et al., 1978; Pszczolkowski, 1987, 1999; Millán, 1997c; Furrazola-Bermúdez, 1997; Pszczolkowski y Myczynski, 2003; Stanek et al., 2006; Iturralde-Vinent, 2012, Iturralde-Vinent y Pszczolkowski, 2012). Abreviaturas: Ac - Fm. Arroyo Cangre; Jg - Fm. Jagua (m = metamorfizada); Gs - Fm. Guasasa (m = metamorfizada); Sc - Fm. San Cayetano; Pn - Fm. Pons; Pñ - Fm. Peñas; Fr - Fm. Francisco; Ar - Fm. Artemisa; St - Fm. Santa Teresa; Cr - Fm. Carmita; PnI - Fm. Pinalilla; Mo - Fm. Moreno; Sb - Fm. El Sábalo; PI - Fm. Polier; Lu - Fm. Lucas; Gj - Fm. Guajaibón; Ca - Fm. Cañada; Dg - Anfibolita Daguilla; As - Fm. Agua Santa; Ge - Grupo Gerona (Scb- Fm. Sierra de Caballo); LI - Fm. Llamágua; Lq - Fm. Loma Quivicán; Lc - Fm. Los Cedros; Sa - Fm. La Sabina; Yg - Fm. Yaguanabo; Et - Fm. El Tambor; Ch - Fm. La Chispa; Fe - Esquistos Verdes Felicidad; Sj - Grupo San 2 Juan; Co - Fm. Cobrito; Lgl - Fm. Loma La Gloria; Ag - Esquistos Algarrobo; He - Fm. Herradura; Bo - Fm. Boquerones. La escala del Tiempo Geológico es según Walker et al. (2013).

mación), Loma Quivicán (carbonatada-silícea), La Sabina (carbonatada-siliciclástica), Yaguanabo (vulcanógeno-carbonatada-siliciclástica) y $\mathrm{El}$ Tambor (metaflyshoide). En la unidad I existe evidencia de metamorfismo en facies de esquistos verdes. La unidad II (metamorfizada en facies de esquistos azules) está integrada por las formaciones La Chispa (siliciclástica), Grupo San Juan, Cobrito (carbonatada), Los Cedros, Loma Quivicán, La Sabina y El Tambor. Intercalados con la Formación La Chispa se encuentran los Esquistos Verdes Felicidad (esencialmente con metavulcanitas). Por su parte, la unidad III se conforma sólo por la Formación Loma La Gloria (siliciclástica), en la que se intercalan los Esquistos Algarrobo y la Formación Cobrito. Se han reportado facies metamórficas de esquistos azules y eclogita para esta unidad (Millán 1997a-c; Dublan et al., 1986; Schneider et al., 2004; García-Casco et al., 2006; Stanek et al., 2006). Finalmente, las formaciones Herradura (siliciclástica), Boquerones (carbonatada), Los Cedros y La Sabina integran la unidad IV, que se metamorfizaron en una facies de esquistos verdes. El metamorfismo observado en el Terreno Escambray está relacionado a la inserción del complejo en una zona de subducción (Millán 1997a-c; Dublan et al., 1986.; Stanek et al., 2006; García-Casco et al., 2006, 2008; Despaigne-Díaz, 
Tabla 1. Relación de posición y edad relativa de las rocas magmáticas y meta-magmáticas en la Cordillera Guaniguanico (elaborada a partir de Pszczolkowski, 1987, 1999; Iturralde-Vinent, 1988b, 1996; Cobiella-Reguera, 1996; Furrazola-Bermúdez, 1997; IturraldeVinent y Pszczolkowski, 2012).

\begin{tabular}{|c|c|c|}
\hline \multirow{2}{*}{ Edad de las unidades } & \multirow{2}{*}{$\begin{array}{c}\text { Unidad } \\
\text { litoestratigráfica } \\
\text { (espesor) }\end{array}$} & $\begin{array}{c}\text { Unidad } \\
\text { Tectónica } \\
\end{array}$ \\
\hline & & (Figura 2A) \\
\hline \multirow{2}{*}{$\begin{array}{l}\text { Jurásico Superior } \\
\text { (Oxfordiano Superior) - } \\
\text { Cretácico Inferior } \\
\text { (Valanginiano) }\end{array}$} & Artemisa & $\begin{array}{l}\text { Rosario Sur y } \\
\text { Rosario Norte }\end{array}$ \\
\hline & $(300-800 \mathrm{~m})$ & (RS y RN) \\
\hline \multirow{2}{*}{$\begin{array}{l}\text { Jurásico Superior } \\
\text { (Oxfordiano Medio - } \\
\text { Superior) }\end{array}$} & Francisco & Rosario Sur \\
\hline & $(25 \mathrm{~m})$ & (RS) \\
\hline \multirow{2}{*}{$\begin{array}{c}\text { Jurásico Superior - } \\
\text { Oxfordiano/¿Kimmeridgiano } \\
\text { temprano }\end{array}$} & El Sábalo & Rosario Norte \\
\hline & $(400 \mathrm{~m})$ & $(\mathrm{RN})$ \\
\hline \multirow{2}{*}{$\begin{array}{l}\text { Jurásico Superior } \\
\text { (Oxfordiano Medio - } \\
\text { Superior) }\end{array}$} & Jagua & Faja Cangre \\
\hline & $(160 \mathrm{~m})$ & (FC) \\
\hline \multirow{2}{*}{$\begin{array}{l}\text { Jurásico Inferior - Jurásico } \\
\text { Superior (Oxfordiano) }\end{array}$} & Arroyo Cangre & Faja Cangre \\
\hline & $(700 \mathrm{~m})$ & (FC) \\
\hline
\end{tabular}

Tabla 2. Relación de posición y edad relativa de las rocas magmáticas y meta-magmáticas en el Terreno Pinos (elaborada a partir de Iturralde-Vinent, 1988b; Millán, 1997b).

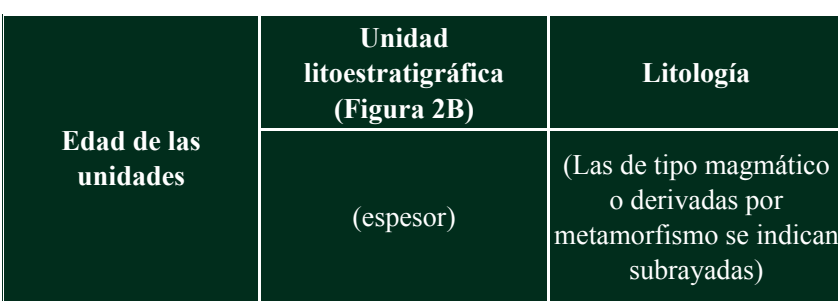

Sierra de Caballos

Jurásico Superior Cretácico Inferior

\section{(Grupo Gerona)}

$(100-200 \mathrm{~m})$

Jurásico Medio-

Anfibolitas Daguilla

Jurásico Superior

( 100 metros)

(Oxfordiano?)
Mármol gris, a veces bandeados, con capas finas de cuarcita metapedernálica, intercalaciones anfibolita, de calcosilicatadas $\quad \mathrm{y}$ mármoles dolomíticos.

Anfibolita intercaladas con rocas calcosilicatadas, mármol y esquisto cuarzo feldespático (Figura 4F).
Calizas con escasos mantos de basalto (Figura 4E).

Limolita y lutita, de estratificación fina a laminar, con intercalaciones de caliza de color gris a negro y escasos mantos de basalto.

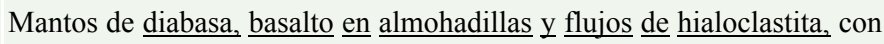
intercalaciones terrígenas en la parte baja del corte (Figura 4D). Hacia arriba contiene estratos calcáreos intercalados. En afloramientos de la parte occidental de RN (Zona Esperanza- Mantua; Figura 2A) hay presente diques y sills de gabros, gabro-diabasa y diabasa, intercalados en calizas y paquetes de areniscas y limonitas.

Caliza micrítica, esquisto arcilloso- margoso y lutita calcárea con intercalaciones de escasos flujos de metabasalto (Figura 4C).

Esquisto terrígeno, metapsamita cuarcíferas con mica blanca e intercalaciones aisladas de caliza, con sills de anfibolita, gabro y diabasa en la parte superior del corte (Figuras 4A,B).

\section{Rocas magmáticas vinculadas al MCP en el occidente y centro de Cuba}

En las Tablas 1-3 se presenta una descripción general de las unidades litoestratigráficas del MCP que contienen rocas magmáticas (la mayoría con evidencia de metamorfismo y alteración), cuyas relaciones geológicas y mineralogía (Tabla 4) se describen a continuación. 
Tabla 3. Relación de posición y edad relativa de las rocas magmáticas y meta-magmáticas en el Terreno Escambray (elaborada a partir de Dublan et al., 1986; Iturralde-Vinent, 1996, 2012; Millán, 1997c).

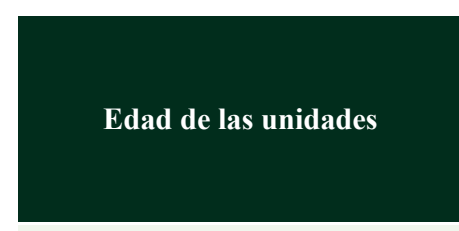

Cretácico

Superior

Cretácico Inferior indiferenciado Cretácico Superior

Cretácico Inferior/Aptiano-

Cretácico Superior/Turoniano

Jurásico Superior (Tithoniano) Cretácico Inferior

Jurásico Superior?

Jurásico Superior- Cretácico Inferior

Jurásico Inferior - Jurásico Superior (Oxfordiano)

Jurásico Inferior - Jurásico Superior (Oxfordiano)

Jurásico Inferior - Jurásico Superior (Oxfordiano)

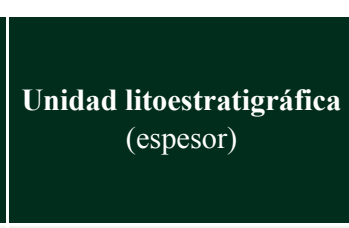

El Tambor

(centenares de metros)

Yaguanabo

(>200 m)

La Sabina

$(>100 \mathrm{~m})$

Los Cedros

(80-100 m)

Boquerones

(100 m)

Cobrito

(400 m)

Esquistos verdes Felicidad (decenas de metros)

La Chispa

(centenares de metros)

Loma La Gloria

(centenares de metros)

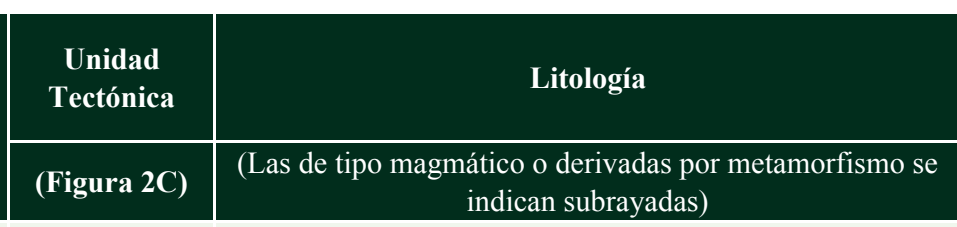

I y II

Metaflisch. Suele contener esquisto terrígeno, mármol gris, metasilicita y metavolcánicos (Figura 4K).

Metavolcánicos básicos (metabasalto, metatoba, metatufitaI y II Figura 4J) a veces con capas de mármol y cuarcita (Figura 4I).

I, II y IV

Esquisto cuarcífero, con intercalaciones de mármol gris, metapsamita y metavolcánicos (Figura 4H).

Mármoles foliados grises con intercalaciones de metasilicita, metapsamita y metavolcánicos básicos.

Mármol negro esquistoso $\mathrm{y}$ esquisto calcítico. Intercalaciones locales de metabasitas.

Mármol esquistos negro y esquisto calcáreo grafítico moscovítico en estratos finos. Intercalaciones de esquisto metaterrígeno, en ocasiones capas de eclogita a veces retrogradada.

Metavolcánicos básicos con capas de mármol negro o gris, esquisto metaterrígeno y cuarcita.

Esquisto cuarzo-moscovítico y filita moscovítica grafítica con intercalaciones de metavolcánicos básicos, esquisto calcáreo y cuarcita.

Esquisto cuarzo-moscovítico, con intercalaciones de mármol y esquisto calcáreo-moscovítico-grafítico, esquisto cristalino (Algarrobo), cuarcita y eclogita en ocasiones retrogradada (Figura $4 \mathrm{G}$ ).

y/o metagabro intercalados en metaterrígenos. Los sills se caracterizan por mostrar una textura lepidogranoblástica con magnesiohornblenda, glaucofana, actinolita, clinozoisita, epidota, albita, clorita y cuarzo (Tabla 4). Esta asociación mineral es indicativa de un metamorfismo en facies de esquistos azules (Figura 4B; Millán, 1972; Somin y Millán, 1981; Gruz-Gámez et al., 2003, 2007). En la Formación Jagua (localidad Mestanza, Pinar del Río) aparecen dos flujos pequeños de metabasalto (espesor $=1.5-2.5 \mathrm{~m})$ separados por esquisto de sericita. Presentan una textura algo orientada con fenocristales de plagioclasa, clorita, epidota, actinolita y hornblenda (Tabla 4; Figura 4C). Tenien- 
Tabla 4. Composición modal (\%) de las rocas magmáticas y meta-magmáticas del Margen Continental Pasivo del occidente y centro de Cuba.

\begin{tabular}{|c|c|c|c|c|c|c|c|c|c|c|c|c|c|c|c|c|}
\hline Minerales & PI & Cpx & Hbl & Act & Gln & Chl & $\mathbf{E p}$ & Grt & Ms & Qtz & Cal & Sph & Tal & Vd & Met & Litología \\
\hline \multicolumn{17}{|c|}{ Arroyo Cangre } \\
\hline CC-09 & 10 & & 50 & 5 & 13 & 5 & 12 & & & 2 & 1 & 1 & & & 1 & MGAf \\
\hline $\mathrm{CC}-10$ & 12 & & 52 & 6 & 10 & 6 & 10 & & & 1 & 1 & 1 & & & 1 & MGAf \\
\hline $\mathrm{CC}-11$ & 10 & & 48 & 8 & 12 & 8 & 9 & & & 2 & 1 & 1 & & & 1 & MGAf \\
\hline FC-1 & 11 & & 50 & 3 & 12 & 5 & 13 & & & 2 & 1 & 2 & & & 1 & MGAf \\
\hline FC-1B & 13 & & 50 & 5 & 10 & 7 & 10 & & & 2 & 1 & 2 & & & & MGAf \\
\hline \multicolumn{17}{|c|}{ Jagua } \\
\hline $\mathrm{Jg}-1$ & 25 & & 5 & 15 & & 25 & 22 & & & 2 & 2 & 2 & & & 2 & MB \\
\hline \multicolumn{17}{|c|}{ Anfibolita Daguilla } \\
\hline IJ-23 & 35 & & 55 & & & & & 7 & & & & 2 & & & 1 & Anfibolita \\
\hline $\mathrm{IJ}-24$ & 35 & & 55 & & & & & 7 & & & & 2 & & & 1 & Anfibolita \\
\hline $\mathrm{IJ}-25$ & 40 & & 47 & & & & & 10 & & & & 2 & & & 1 & Anfibolita \\
\hline IJ-26 & 35 & & 62 & & & & & & & & & 2 & & & 1 & Anfibolita \\
\hline \multicolumn{17}{|c|}{ (W Rosario Norte- Mantua) } \\
\hline $\mathrm{k}-18$ & 55 & 40 & & & & 2 & & & & & 2 & & & & 1 & Diabasa \\
\hline $\mathrm{k}-19$ & 53 & 43 & & & & 2 & & & & & 1 & & & & 1 & Diabasa \\
\hline \multicolumn{17}{|c|}{ Artemisa } \\
\hline 6800 & 78 & & & & & 3 & & & & & 4 & & & 15 & & Basalto \\
\hline \multicolumn{17}{|c|}{ Loma La Gloria } \\
\hline SM-82 & 28 & 1 & & 20 & 5 & 15 & 10 & 10 & 5 & 5 & & 1 & & & & Eclogita \\
\hline SM- $82 b$ & 25 & & & 22 & 4 & 17 & 13 & 10 & 3 & 5 & & 1 & & & & Eclogita \\
\hline \multicolumn{17}{|c|}{ La Sabina } \\
\hline CG-7b & & & & 75 & & & & & & & & & 25 & & & EAc \\
\hline \multicolumn{17}{|c|}{ Yaguanabo } \\
\hline YG-15c & 30 & 2 & & 20 & & 13 & 30 & & & & 2 & 2 & & & 1 & EEp \\
\hline \multicolumn{17}{|c|}{ El Tambor } \\
\hline 7CF-8B & 15 & & & & & 20 & 50 & & 5 & & 9 & 1 & & & & EEp \\
\hline YG-22 & 25 & & & 10 & & 20 & 25 & & 10 & & 5 & 3 & & & & EEp \\
\hline SR-62 & 20 & & & 30 & 10 & 15 & 15 & & 10 & & & & & & & EAc \\
\hline
\end{tabular}

Claves de minerales: PI-plagioclasa, Al-albita, Opx-ortopiroxeno, Hbl-hornblenda, Act-actinolita, Gln-glaucofana, Chl-clorita, Epepidota, Grt-granate, Ms-moscovita, Qtz-cuarzo, Cal-calcita, Sph-esfena, Tal-talco, Vd-vidrio volcánico y Met-metálicos. Para las litologías: MGAf-metagabro anfibolizado; MB-metabasalto; EAc-esquisto actinolítico; EEp-esquisto epidótico

do en cuenta la mineralogía, se ha inferido una facies metamórfica de esquistos verdes (Millán, 1972, 1987; Gruz-Gámez et al., 2007). Generalmente esta secuencia no aparece metamorfizada en el resto de la Cordillera.
En las unidades tectónicas Rosario Norte y Sur (Figura 3; Tabla 1), las rocas magmáticas se presentan en la Zona Esperanza ( $\mathrm{N}$ de Mantua; Figura 2A) y en las formaciones El Sábalo (Jurásico Superior/Oxfordiano Superior - Kimmeridgiano tem- 

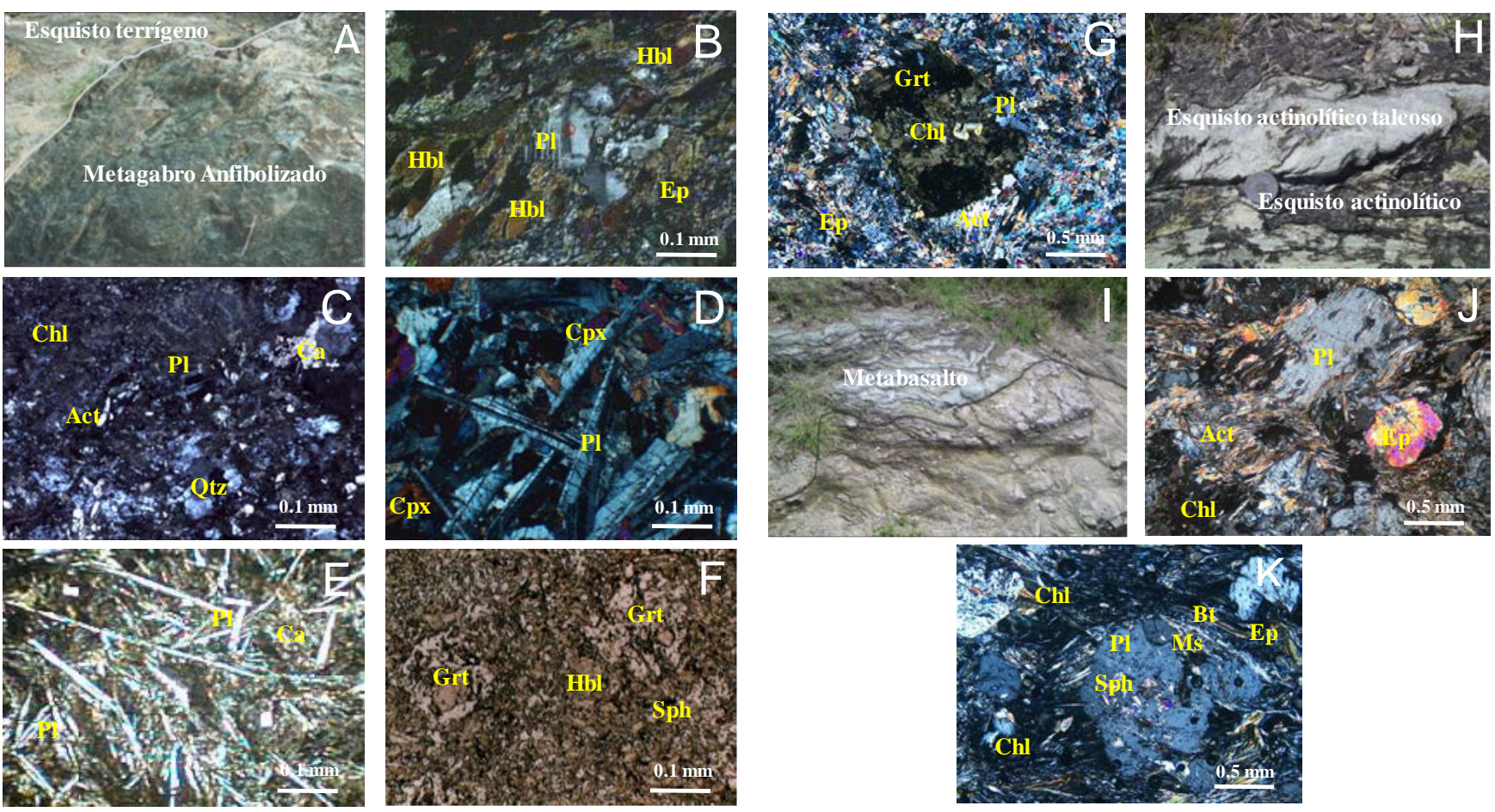

Figura 4 Fotos de afloramientos y microfotografías de rocas magmáticas y meta-magmáticas (ubicación en Tablas 5-7 y símbolos de minerales en Tabla 4) asociadas al Margen Continental Pasivo: (A) Sill de metagabro en el río Cangre, intercalado en esquistos terrígenos, Formación Arroyo Cangre- espesor 12 m / Cordillera de Guaniguanico; (B) Muestra CC-09 de este afloramiento: Metagabro con hornblenda, plagioclasa, glaucofana, epidota, actinolita y clorita (CN, 10x); (C) Muestra Jg-1, Formación Jagua / Cordillera de Guaniguanico: Metabasalto con epidota, clorita, plagioclasa, actinolita y, calcita y cuarzo secundario (CN, 10x); (D) Muestra Cu03-13 (Allibon et al., 2008), Formación El Sábalo / Cordillera de Guaniguanico: Diabasa con plagioclasa y clinopiroxeno y, textura ofítica (CN, 10x); (E) Muestra 6800, Formación Artemisa / Cordillera de Guaniguanico: Basalto afírico con plagioclasa formando textura intersertal, y calcita secundaria (CN, 10x); (F) Muestra IJ-24, Anfiboita Daguilla / Terreno Pinos: Anfibolita con abundante hornblenda y granate (SN, 10x); (G) Muestra SM-82, Formación Loma La Gloria / Terreno Escambray: Eclogita con grado de retrogresión a facie de los esquistos verdes, con pórfidos de granate euhedral reemplazados por clorita, en una matriz de albita, epidota, clorita, actinolita y esfena (CN, 20x); (H) Esquisto actinolítico en ocasiones talcoso microplegado del valle de Yaguanabo, Formación La Sabina- espesor $\sim 1 \mathrm{~m} /$ Terreno Escambray; (I) Cuerpo de metabasalto con diferente coloración bajo el efecto del intemperismo (Valle de Yaguanabo), Formación Yaguanabo- espesor 3.5 m / Terreno Escambray; (J) Muestra YG-15c de este afloramiento: Esquisto con pórfidos de plagioclasa en una matriz de actinolita, epidota y clorita (CN, 4x); (K) Muestra SR-62, Formación El Tambor / Terreno Escambray: Esquisto con pórfidos de plagioclasa (albita) en una matriz de clorita, actinolita, micas y epidota.

prano?), Francisco (Jurásico Superior/Oxfordiano Medio) y Artemisa (Jurásico Superior/Oxfordiano Superior - Cretácico Inferior/Valanginiano). La Formación El Sábalo (localidad: Los Hoyos, carretera de montaña al $\mathrm{N}$ de Soroa) está integrada por diabasa y basalto (con espesores de $\sim 25 \mathrm{~m}$ ), con estructura en almohadillas, intercalados por hialoclastita y, ocasionalmente, por horizontes de caliza biogénica y pizarra calcáreo-arcillosa de estratificación fina (que contiene microfósiles del pre-Oxfordiano Superior; Pszczolkowski y Albear, 1983; Pszczolkowski, 1999). La diabasa se carac- teriza por una textura ofítica o poiquilítica, que incluye plagioclasa, a veces con inclusiones de apatito, clinopiroxeno y magnetita, acompañados de clorita y anfíbol postmagmático (Figura 4D). El basalto muestra textura intersertal, subofítica y variolítica. Está constituido principalmente por plagioclasa, clinopiroxeno alterado a carbonatos y clorita, pirita distribuida de forma irregular y titanomagnetita embebidos en una matriz vítrea. Las alteraciones secundarias fundamentales son cloritización, zeolitización y carbonatización, vinculadas al vidrio volcánico. Pszczolkowski (1999) 
indicó una edad para esta secuencia a partir de su posición y contenido faunístico de Oxfordiano Superior - Kimmeridgiano temprano? y, Allibon et al. (2008) basados en los valores de $\Sigma \mathrm{Nd}$ asignaron una edad de 150 a $165 \mathrm{Ma}$ al magmatismo asociado.

Por otra parte, en la porción W de la unidad Rosario Norte, en la llamada Zona Esperanza, al N de Mantua (Figura 2A), Segura-Soto et al. (1985) reportaron por datos de perforación numerosos cuerpos de gabro, diabasa y basalto $(\sim 20 \mathrm{~m})$, en forma de sills o diques, entre caliza, arenisca y limolita considerados por Cobiella-Reguera (1996) correlacionables en edad con las mafitas de la Formación El Sábalo (Tabla 1). El gabro, de textura granular y poiquilítica, está constituido por plagioclasa (labradorita) y clinopiroxeno xenomórfico, parcialmente uralitizado y un tanto fibroso. La diabasa muestra una textura ofítica e incluye una asociación con plagioclasa (andesina) y clinopiroxeno (Tabla 4) muy afectada, al igual que el gabro, por cloritización, sericitización y albitización.

En la parte alta de algunos cortes de la Formación Francisco (localidad Cinco Pesos, San Cristóbal), Pszczolkowski (1978) reportó flujos de basalto con albita ( $\sim 0.5 \mathrm{~m}$ de espesor), dentro de caliza laminada y arenisca, para los que no existe información petrográfica detallada disponible. El último evento magmático dentro de las unidades Rosario fue reportado por Martínez et al. (1991) en algunas secciones de la Formación Artemisa, en particular a $2 \mathrm{~km}$ al W del poblado Cinco Pesos, San Cristóbal. Estos fueron descritos como mantos concordantes de basalto ( $\sim 8 \mathrm{~m}$ de espesor) entre caliza, muy alterados por la carbonatación y cloritización. Se caracterizan por texturas de tipos oligofírica-amigdaloidal, que incluye escasos fenocristales de plagioclasa totalmente sericitizada, que también integran la matriz intersticial como microlitos junto al vidrio (Tabla 4; Figura 4E). Se reportan amígdalas rellenas por clorita y carbonato (Martínez et al., 1991).

\subsection{TERRENO PINOS}

Dentro de la secuencia meta-sedimentaria jurásica del MCP en la Isla de la Juventud se ha reportado la presencia de rocas anfibolíticas (Tabla 2): (a) formando una escama tectónica independiente Anfibolita Daguilla, Jurásico Medio-Jurásico Superior/Oxfordiano?), intercalada con mármol y esquisto cuarzo-feldespático (paquetes de $\sim 100$ m), al SE de La Fe (Millán, 1975; González, 2013; Figura 2B) y representa una destacada elevación (Loma Daguilla) en la región, ya que alcanza una altura de hasta $185 \mathrm{~m}$ sobre una planicie de escasos metros de altura sobre el nivel del mar, y (b) un cuerpo intercalado en estratos de mármol y cuarcita de la Formación Sierra de Caballos (Jurásico Superior - Cretácico Inferior; Figura 3), al SE de la ciudad de Nueva Gerona (Millán, 1997b). Las anfibolitas de la Isla de la Juventud se componen de hornblenda, plagioclasa (oligoclasa-andesina), magnetita, esfena, clinopiroxeno y granate (Tabla 4; Figura 4F; Millán, 1981).

\subsection{TERRENO ESCAMBRAY}

En las secuencias estratigráficas de este terreno, en el intervalo Jurásico Inferior -Cretácico Superior, se ha reportado la presencia de rocas magmáticas metamorfizadas (Stanik et al., 1981; Millán y Somin, 1985b; Dublan et al., 1986; Iturralde-Vinent, 1988b, 1996). Como ya se ha señalado, éstas ocurren en las formaciones Loma La Gloria, La Chispa, Cobrito, Boquerones, Los Cedros, La Sabina, Yaguanabo y El Tambor, así como en los Esquistos Verdes Felicidad (Figura 3; Tabla 3).

Las eclogitas de la Formación Loma La Gloria (Jurásico Inferior - Jurásico Superior/Oxfordiano; espesor $\sim 1.5 \mathrm{~m}$, localidad Monforte, provincia de Cienfuegos), algunas retrogradas, presentan una textura granoblástica e incluyen granate, onfacita, epidota, actinolita, glaucofana, paragonita, fengita, cuarzo, albita, clorita y esfena, embebidos en una matriz donde predomina mica y epidota (Tabla 4; Figura 4G; Millán y Álvarez-Sánchez, 
1992; Millán 1997c; Despaigne-Díaz, 2009). Estas rocas están intercaladas con esquistos cuarzo ó calcáreo-moscovítico-grafítico, mármol y cuarcita (Tabla 3). Millán (1997c) indicó que, con frecuencia, entre estas rocas y la eclogita existe una litología tipo transicional que sugiere una interacción metasomática o una antigua aureola de contacto magmático. Schneider et al. (2004) señalaron, a partir de su composición en elementos traza, que el origen de estas eclogitas en la cúpula de Sancti Spíritus está ligado a un ambiente de arco volcánico, lo que se discutirá más adelante en el presente trabajo. Dentro de la unidad III se distribuyen escamas de serpentinita (con antigorita) que contienen bloques de eclogita. Schneider et al. (2004) indicaron un origen tipo MORB. Este tipo de metabasita no es objeto del presente estudio.

Esquistos verdes de protolitos volcánicos (con intercalaciones rítmicas de $30 \mathrm{~cm}$ ), se han reportado en la Formación La Chispa (Cúpula de Trinidad; Jurásico Inferior a Superior/Oxfordiano), que incluye además esquisto cuarzo-moscovítico y filita moscovítica- grafitica, con intercalaciones de esquisto calcáreo y cuarcita (Stanik et al., 1981; Millán y Somin, 1985b; Tabla 3). En esta formación también aparecen otras metavulcanitas básicas (esquistos verdes con lawsonita y piroxeno; Millán y Somin, 1985b), denominadas "Esquistos Verdes Felicidad" (Jurásico Inferior a Superior). Se presentan con espesores que pueden alcanzar desde decenas hasta un centenar de metros, intercalados con capas de mármol negro o gris, esquistos metaterrígenos y cuarcita (Iturralde-Vinent, 1996; Figura 3, Tabla 3).

En la Formación Cobrito (Jurásico Superior- Cretácico Inferior basal) se han reportado (Cúpula de Trinidad, al SE del poblado La Sierrita) eclogitas retrogradas en facies de esquistos verdes, compuestas por actinolita, clorita, epidota, zoisita, granate, esfena y albita, formando bloques concordantes $(<1.5 \mathrm{~m})$ entre mármol esquistoso (Millán y Somin, 1985b; Millán y Álvarez-Sánchez, 1992; Despaigne-Díaz, 2009, Despaigne-Díaz et al., 2016). En la Formación Boquerones (Jurásico Superior) ocurren muy localmente metabasitas, relacionadas con mármol negro y esquisto calcáreo grafítico-moscovítico, formando estratos muy finos de carácter rítmico (Millán, 1997c). En la Formación Los Cedros (Jurásico Superior/Tithoniano - Cretácico Inferior) aparecen esquistos verdes metavolcánicos en las elevaciones de Quemado de Los Cedros (Cúpula de Trinidad) a 1 km al NW del poblado de San José. Se componen de plagioclasa, clorita, actinolita, y esfena. Están intercalados en mármol gris (con moscovita, cuarzo y grafito), de estratos finos y laminados, y en ocasiones con capas de metasilicita (con moscovita y granate) (Millán y Álvarez-Sánchez, 1992; Despaigne-Díaz, 2009; Tabla 3).

En la Formación La Sabina (Cretácico Inferior/ Aptiano - Cretácico Superior/Turoniano) se reconocen, en la localidad La Sierrita (provincia de Cienfuegos), esquistos verdes metavolcánicos de textura nematoblástica compuestos por actinolita, clorita, epidota, albita \pm talco (Tabla 4). A veces conservan la fábrica magmática primaria y relictos de clinopiroxeno y plagioclasa (espesor $\sim 2 \mathrm{~m}$ ). Éstos ocurren dentro de una sucesión de cuarcita y metasilicita bien estratificada y bandeada, con frecuencia granatíferas, con intercalaciones de mármol gris y metapsamita (Millán, 1997c; Tabla 3, Figura 4H). En el Valle de Yaguanabo (Cúpula de Trinidad), la Formación Yaguanabo (Cretácico Inferior - Cretácico Superior) incluye metavulcanitas básicas (hasta 4.5 m, se repiten en el corte; Figura 4I) en facies de esquistos verdes, acompañados de mármol y cuarcita (Millán, 1997c; Tabla 3). Éstos corresponden a esquisto feldespático, con textura pórfido-lepidoblástica, y que incluyen plagioclasa, epidota, actinolita y clorita (Figura 4J). En ocasiones se reporta la presencia de esquisto actinolítico talcoso, con antigorita y hornblenda relíctica escasa, de textura lepidoblástica, posiblemente derivados de un protolito ultramáfico (Stanik et al., 1981; Dublan et al., 1986; Despaigne-Díaz, 2009). La Formación Yaguanabo constituye una sucesión de esquistos verdes con textura-estructura primaria, conformados de metatoba, metatufita, metaglomerado y metalava porfírica (Stanik et al., 1981; Dublan et al., 1986; Millán y Somín, 1985a). La 
Formación El Tambor (Cretácico Superior por su posición estratigráfica, Figura 3) al E del poblado San Blas (carretera La Sierrita-Topes de Collantes) presenta esquistos verdes metavolcánicos con albita, actinolita, clorita, mica, biotita, epidota y esfena (espesor $\sim 2.5 \mathrm{~m}$; Figura 4K), intercalados por esquistos cuyo protolito son sedimentos de tipo flysch (en facies de esquisto verde) y, en ocasiones, por mármol y metasilicita (Millán y Somín, 1985a; Tabla 3).

\section{Métodos analíticos y manejo de información}

Durante el presente estudio se determinó la composición química en 20 muestras de rocas magmáticas y meta-magmáticas incluidas en las series sedimentarias y metasedimentarias, respectivamente, del MCP del occidente y centro de Cuba (Tablas 5-7). Las muestras correspondientes a las formaciones El Sábalo, Zona Esperanza y Artemisa (basalto, diabasa y gabro) no indican evidencia de metamorfismo. El resto incluyen metavolcánico, metadiabasa, metagabro metamorfizado en facies variadas (esquistos verdes, esquistos azules, eclogitas y anfibolitas).

Un primer grupo de muestras fue analizado en el Centro de Instrumentación Científica (CIC) de la Universidad de Granada, España (Tablas 5-6). Los elementos mayores y el $\mathrm{Zr}$ fueron determinados en perlas de vidrio (generadas por fusión de la muestra con tetraborato de litio, con un sistema de fluorescencia de rayos-X (XRF) Philips Magix Pro (PW-2440). La precisión analítica típica fue de $\pm 1.5 \%$ para una concentración de analito de 10 $\%$. La composición en elementos mayores se complementó con el \% de perdida por ignición (\%PPI) a $1000{ }^{\circ} \mathrm{C}$. La concentración de elementos traza fue determinada en una solución generada por digestión de $0.1000 \mathrm{~g}$ de muestra con $\mathrm{HNO}_{3}+\mathrm{HF}$ en una bomba de teflón a $180{ }^{\circ} \mathrm{C}$ y 200 psi por 30 minutos, seguida de evaporación y la recuperación con $100 \mathrm{ml}$ de $\mathrm{HNO}_{3}$ al $4 \%$ en volumen. La solución fue inyectada en un sistema NEXION
300 d de espectrometría de masas con cuadrupolo acoplado a plasma de forma inductiva (ICP-MS). La precisión analítica fue superior a $\pm 5 \%$ para concentraciones de analito de aproximadamente $10 \mathrm{ppm}$. La concentración de Hf fue inferida a partir de la relación $\mathrm{Zr} / \mathrm{Hf}$ (generada desde el análisis ICP-MS) y la concentración de $\mathrm{Zr}$ (generada por XRF).

La composición de elementos mayores y traza de un segundo grupo de muestras se estableció por XRF en el Instituto de Geografía y Geología de la Universidad Ernst-Moritz-Arndt de Greisfwald, Alemania (Tablas 5-7). El análisis se efectuó en perlas de vidrio generadas desde un fundido, obtenido a $1100{ }^{\circ} \mathrm{C}$, de la muestra mezclada en relación 1:4 con un fundente de tetraborato de litio- metaborato de litio. La determinación se realizó en un sistema XRF Philips PW 2404, con una precisión de $\sim 1-2 \%$ para los elementos mayores y $<5 \%$ para los de tipo traza. La composición de elementos mayores fue complementada con el $\%$ PPI, determinado a $1000{ }^{\circ} \mathrm{C}$.

Se preparó una base de datos con la información generada, la cual se complementó con 12 muestras adicionales, cuya composición está disponible en trabajos previos (Cobiella-Reguera, 1996 [muestras: 8, 9, 10 y 11; Zona Esperanza, W de Rosario Norte]; Kerr et al., 1999 [muestra SAB1; Soroa, Formación El Sábalo]; Stanik et al., 1981 [muestra M-1; Unidad I, Cúpula de Trinidad, Formación La Sabina]; Schneider et al., 2004 [muestras: CU16 y LV66; Unidad III, Cúpula Sancti Spíritu, Formación Loma La Gloria]; González y Meriño, 2005 [muestra AD-1- Loma Daguilla]; Allibon et al., 2008 [muestras: Gu03-13, Cu03-14, Cu03-15; Soroa, Formación El Sábalo]). Dado el carácter alterado-metamorfizado de las muestras, se utilizó el diagrama $\mathrm{Zr} / \mathrm{Ti}-\mathrm{Nb} / \mathrm{Y}$ (Winchester y Floyd, 1977; Pearce, 1996) para clasificar las rocas. Por otra parte, las muestras se graficaron en un diagrama $\mathrm{Al}_{2} \mathrm{O}_{3}{ }^{*}-\mathrm{CaO} *-\mathrm{FeO} *$ molar o ACF calculado mediante proyección desde fases vectores de intercambio apropiados utilizando el software CSpace (Torres-Roldán et al., 2000), a fin de evaluar los potenciales efectos de la asimilación 
Tabla 5. Composición química de las rocas magmáticas y meta-magmáticas para la Cordillera de Guaniguanico.

\begin{tabular}{|c|c|c|c|c|c|c|c|c|c|}
\hline Formación & \multicolumn{5}{|c|}{ Arroyo Cangre } & Jagua & \multirow{2}{*}{\multicolumn{2}{|c|}{$\frac{-}{\text { Zona Esperanza }}$}} & Artemisa \\
\hline Localidad & \multicolumn{5}{|c|}{ Río Cangre - Guabina } & Mestanza & & & Sierra Rosario \\
\hline Muestra & $\mathrm{CC}-09^{a}$ & $\mathrm{CC}-10^{a}$ & $\mathrm{CC}-11^{a}$ & $\mathrm{FC}-1^{b}$ & FC- $1 B^{b}$ & $\mathrm{Jg}-1^{b}$ & $\mathrm{k}-18^{a}$ & $\mathrm{k}-19^{a}$ & $6800^{a}$ \\
\hline Longitud & $215119 \mathrm{E}$ & $215119 \mathrm{E}$ & $215119 \mathrm{E}$ & $215119 \mathrm{E}$ & $215119 \mathrm{E}$ & $213778 \mathrm{E}$ & $778852 \mathrm{E}$ & $778852 \mathrm{E}$ & $286083 \mathrm{E}$ \\
\hline Latitud & $2485739 \mathrm{~N}$ & $2485740 \mathrm{~N}$ & $2485741 \mathrm{~N}$ & $2485738 \mathrm{~N}$ & $2485737 \mathrm{~N}$ & $2486547 \mathrm{~N}$ & $2474042 \mathrm{~N}$ & $2474042 \mathrm{~N}$ & $2525557 \mathrm{~N}$ \\
\hline Litología & MGAf & MGAf & MGAf & MGAf & MGAf & MB & DB & DB & B \\
\hline
\end{tabular}

\begin{tabular}{|c|c|c|c|c|c|c|c|c|c|}
\hline \multicolumn{10}{|c|}{ Elementos mayores (\% en peso) } \\
\hline $\mathrm{SiO}_{2}$ & 49.01 & 48.6 & 49.17 & 47.23 & 46.79 & 39.9 & 46.42 & 48.06 & 45.97 \\
\hline $\mathrm{TiO}_{2}$ & 2.06 & 2.78 & 2.62 & 2.85 & 2.62 & 2.65 & 1.5 & 1.2 & 2.21 \\
\hline $\mathrm{Al}_{2} \mathrm{O}_{3}$ & 13.55 & 12.96 & 14.36 & 12.91 & 13.4 & 14.36 & 14.65 & 14.9 & 12.99 \\
\hline $\mathrm{FeO}^{\mathrm{t}}$ & 11.7 & 13.3 & 11.11 & 15.65 & 15.16 & 11.29 & 11.97 & 11.31 & 11.44 \\
\hline $\mathrm{MnO}$ & 0.25 & 0.25 & 0.25 & 0.22 & 0.28 & 0.21 & 0.42 & 0.47 & 0.1 \\
\hline $\mathrm{MgO}$ & 7.14 & 6.87 & 6.08 & 5.72 & 6.76 & 12.27 & 10.95 & 8.55 & 9.96 \\
\hline $\mathrm{CaO}$ & 9.03 & 8.09 & 7.65 & 8.99 & 8.46 & 9.95 & 8.4 & 9.82 & 10.89 \\
\hline $\mathrm{Na}_{2} \mathrm{O}$ & 3.2 & 3.59 & 3.86 & 3.48 & 3.07 & 1.37 & 1.73 & 2.07 & 1.99 \\
\hline $\mathrm{K}_{2} \mathrm{O}$ & 0.37 & 0.46 & 0.85 & 0.4 & 0.4 & 0.5 & 0.5 & 0.5 & 0.27 \\
\hline $\mathrm{P}_{2} \mathrm{O}_{5}$ & 0.23 & 0.25 & 0.17 & 0.26 & 0.24 & 0.52 & 0.02 & 0.01 & 0.68 \\
\hline PPI & 3.35 & 3.12 & 2.63 & 2.09 & 2.39 & 6.2 & 2.48 & 2.11 & 2.5 \\
\hline Suma & 99.89 & 100.27 & 99 & 99.8 & 99.57 & 99.22 & 99.04 & 99.59 & 99 \\
\hline
\end{tabular}

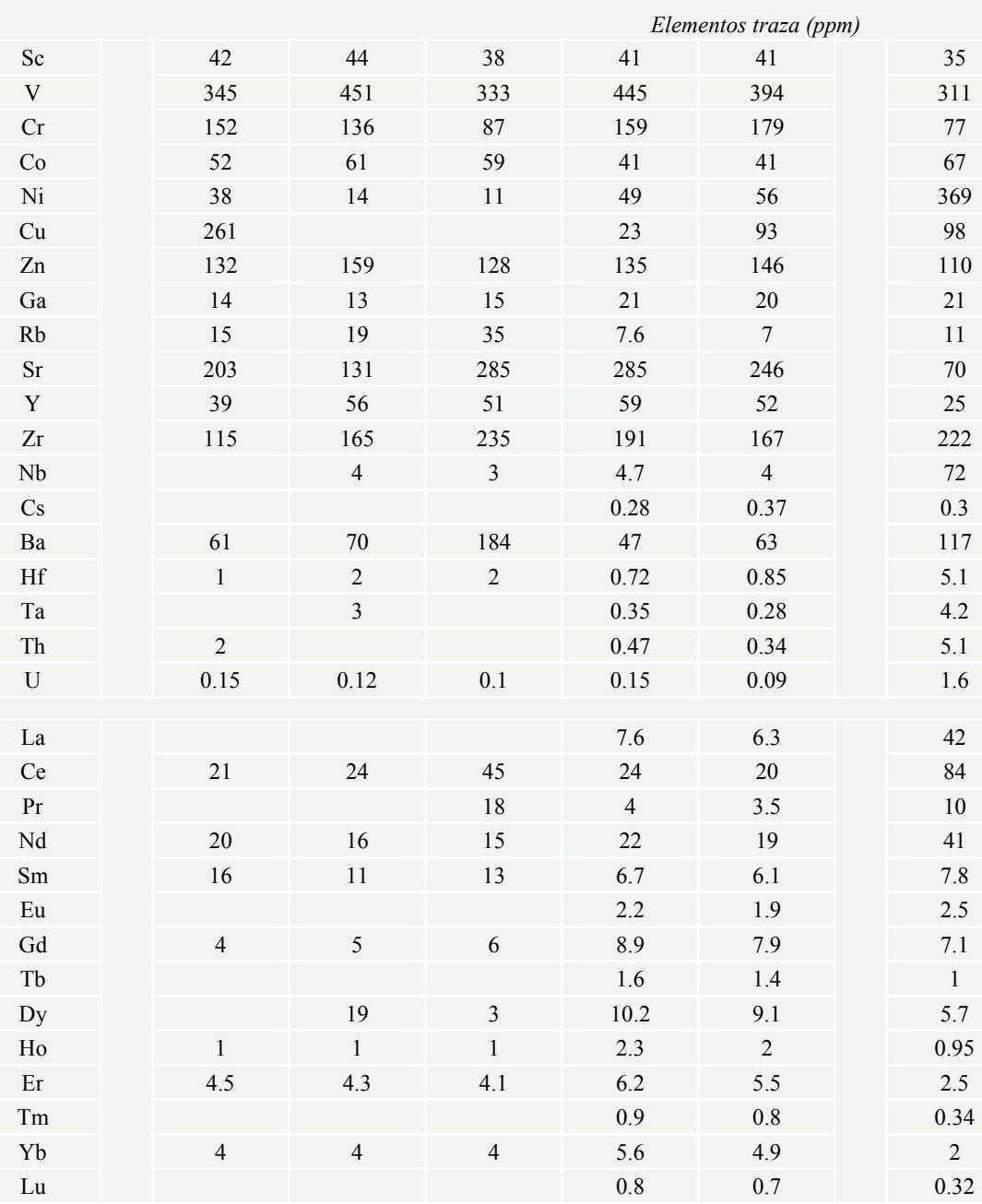

PPI = Pérdida por ignición. Litologías: $\mathrm{DB}=$ diabasa, $\mathrm{B}=$ basalto (resto de símbolos como en Tabla 4). a) laboratorio del Instituto de Geografía y Geología de la Universidad Ernst-Moritz-Arndt (Greisfwald, Alemania) y b) Laboratorio del Centro de Instrumentación Científica de la Universidad de Granada (España). 
Tabla 6. Composición química de las rocas meta-magmáticas para el Terreno Pinos.

\begin{tabular}{c|c|c|c|c|} 
Unidad & \multicolumn{4}{|c|}{ Anfibolita Daguilla } \\
\cline { 3 - 5 } Localidad & \multicolumn{4}{|c|}{ La Fe, Isla de la Juventud } \\
\cline { 1 - 4 } Muestra & \multicolumn{1}{|c|}{$\mathrm{IJ}^{2} 23^{b}$} & $\mathrm{IJ}-24^{b}$ & $\mathrm{IJ}-25^{b}$ & $\mathrm{IJ}^{b}-26^{b}$ \\
\hline Longitud & $323873 \mathrm{E}$ & $323850 \mathrm{E}$ & $323860 \mathrm{E}$ & $323834 \mathrm{E}$ \\
\hline Latitud & $2397390 \mathrm{~N}$ & $2397400 \mathrm{~N}$ & $2397410 \mathrm{~N}$ & $2397339 \mathrm{~N}$ \\
\hline Litología & $\mathrm{AF}$ & $\mathrm{AF}$ & $\mathrm{AF}$ & $\mathrm{AF}$
\end{tabular}

Elementos mayores (\% en peso)

\begin{tabular}{|c|c|c|c|c|}
\hline \multicolumn{5}{|c|}{ Elementos mayores (\% en peso) } \\
\hline $\mathrm{SiO}_{2}$ & 49.62 & 49.5 & 49.78 & 51.43 \\
\hline $\mathrm{TiO}_{2}$ & 0.96 & 0.93 & 0.87 & 1.04 \\
\hline $\mathrm{Al}_{2} \mathrm{O}_{3}$ & 15.28 & 15.2 & 16.18 & 12.88 \\
\hline $\mathrm{FeO}^{\mathrm{t}}$ & 11.52 & 11.21 & 10.43 & 11.72 \\
\hline $\mathrm{MnO}$ & 0.19 & 0.18 & 0.15 & 0.17 \\
\hline $\mathrm{MgO}$ & 7.83 & 7.86 & 7.56 & 8.07 \\
\hline $\mathrm{CaO}$ & 11.51 & 12.9 & 11.61 & 12.11 \\
\hline $\mathrm{Na}_{2} \mathrm{O}$ & 1.6 & 0.86 & 1.95 & 1.47 \\
\hline $\mathrm{K}_{2} \mathrm{O}$ & 0.22 & 0.13 & 0.22 & 0.2 \\
\hline $\mathrm{P}_{2} \mathrm{O}_{5}$ & 0.08 & 0.09 & 0.08 & 0.1 \\
\hline PPI & 0.92 & 0.92 & 0.92 & 0.92 \\
\hline Suma & 99.73 & 99.78 & 99.75 & 100.11 \\
\hline
\end{tabular}

\begin{tabular}{|c|c|c|c|c|}
\hline \multicolumn{5}{|c|}{ Elementos traza (ppm) } \\
\hline Sc & 47 & 45 & 40 & 50 \\
\hline $\mathrm{V}$ & 352 & 351 & 304 & 367 \\
\hline $\mathrm{Cr}$ & 347 & 324 & 387 & 381 \\
\hline Co & 45 & 44 & 43 & 43 \\
\hline $\mathrm{Ni}$ & 106 & 108 & 116 & 71 \\
\hline $\mathrm{Cu}$ & 57 & 37 & 74 & 71 \\
\hline $\mathrm{Zn}$ & 82 & 72 & 72 & 82 \\
\hline G & 17 & 17 & 16 & 15 \\
\hline $2 b$ & 5.7 & 5 & 6 & 5 \\
\hline $\mathrm{Sr}$ & 130 & 139 & 154 & 89 \\
\hline Y & 26 & 25 & 22 & 27 \\
\hline $\mathrm{Zr}$ & 49 & 46 & 43 & 54 \\
\hline $\mathrm{Nb}$ & 4.1 & 4 & 3.5 & 4.2 \\
\hline Cs & 0.79 & 0.23 & 0.57 & 0.08 \\
\hline Ba & 27 & 25 & 27 & 7.7 \\
\hline $\mathrm{Hf}$ & 0.35 & 0.35 & 0.34 & 0.45 \\
\hline Га & 0.32 & 0.32 & 0.21 & 0.34 \\
\hline$\Gamma \mathrm{h}$ & 0.29 & 0.27 & 0.25 & 0.31 \\
\hline U & 0.07 & 0.05 & 0.04 & 0.06 \\
\hline $\mathrm{La}$ & 3 & 3.1 & 2.7 & 3.2 \\
\hline $\mathrm{Ce}$ & 7.9 & 7.7 & 6.7 & 8 \\
\hline $\operatorname{Pr}$ & 1.3 & 1.2 & 1.1 & 1.3 \\
\hline $\mathrm{Nd}$ & 6.3 & 6.5 & 5.7 & 6 \\
\hline$\frac{10}{2}$ & 2.2 & 2.3 & 2 & 2.3 \\
\hline$E$ & 0.9 & 0.9 & 0.8 & 0.9 \\
\hline $\mathrm{Gd}$ & 3.3 & 3.2 & 2.7 & 3.5 \\
\hline$\Gamma \mathrm{b}$ & 0.6 & 0.6 & 0.5 & 0.7 \\
\hline Dy & 4.3 & 4.1 & 3.6 & 4.4 \\
\hline Hc & 1 & 0.9 & 0.8 & 1 \\
\hline Er & 2.7 & 2.6 & 2.4 & 2.9 \\
\hline$[\mathrm{n}$ & 0.43 & 0.4 & 0.34 & 0.5 \\
\hline Yl & 2.7 & 2.6 & 2.2 & 2.8 \\
\hline $\mathrm{Cu}$ & 0.42 & 0.41 & 0.36 & 0.5 \\
\hline
\end{tabular}

PPI = Pérdida por ignición. Litología: AF = anfibolita. de sedimentos, alteración pre-metamórfica y metasomatismo en las muestras estudiadas.

Dada la diversidad en litología y grado de metamorfismo observada en las rocas bajo estudio, se realizó un análisis jerárquico de agrupamiento (Hierarchical cluster analysis; Bratchell, 1989), con la finalidad de identificar estadísticamente dominios de rocas con una similitud geoquímica. El análisis se llevó a cabo considerando el logaritmo de relaciones de elementos mayores $\left(\mathrm{SiO}_{2}, \mathrm{TiO}_{2}, \mathrm{FeO}\right.$, $\mathrm{Fe}_{2} \mathrm{O}_{3}$ y $\mathrm{MgO}$; en $\%$ peso normalizados a análisis anhidro) y traza (lantánidos: Ce y Nd, litófilos: $\mathrm{Ba}$ y Sr, alta carga electrostática: $\mathrm{Y}, \mathrm{Zr}$ y Nb, transición: $\mathrm{Ni}$; en ppm) a $\mathrm{Al}_{2} \mathrm{O}_{3}$ (en \% peso normalizado). Este último elemento se consideró como denominador común en las relaciones, debido a su carácter relativamente inmóvil ante la alteración y el metamorfismo (Rollinson, 1993). De acuerdo a la disponibilidad de datos geoquímicos, en esta evaluación se consideraron muestras de las secuencias Arroyo Cangre, Jagua, El Sábalo, Anfibolita Daguilla, Loma La Gloria, Yaguanabo y El Tambor. Antes de efectuar el análisis, los logaritmos de las relaciones geoquímicas fueron estandarizados y el proceso iterativo de encadenamiento de las muestras siguió la regla de Ward (1963). Los resultados del análisis se utilizaron para generar un dendograma en valores euclideanos. Para mayor detalle del procedimiento estadístico consultar a Velasco-Tapia (2014).

Por otra parte, con el propósito de comparar las características geoquímicas entre las rocas estudiadas, se prepararon diagramas de tipo multi-elemento y de lantánidos, normalizados, respectivamente, a basalto de cresta oceánica o MORB (mid-ocean ridge basalt; Pearce, 1982) y a condrita (Haskin et al., 1968; Nakamura, 1974). El esquema de análisis también incluyó la aplicación de diversos diagramas de relaciones geoquímicas (por ejemplo, (a) diagramas $\mathrm{Ba}-\mathrm{Nb}-\mathrm{Nb} / \mathrm{Y}, \mathrm{Nb} /$ $\mathrm{Yb}-\mathrm{Th} / \mathrm{Yb}$ y Nb/Yb-TiO 2 (Pearce, 2008, 2014); y (b) funciones discriminantes multidimensionales, basadas en el logaritmo de relaciones de elementos mayores (Verma et al., 2006), con el propósito de determinar la afinidad tectónica de las rocas. 
Tabla 7. Composición química de las rocas magmáticas y meta-magmáticas para el Terreno Escambray.

\begin{tabular}{|c|c|c|c|c|c|c|c|}
\hline \multirow{2}{*}{$\begin{array}{c}\text { Formación } \\
\text { Localidad }\end{array}$} & \multirow{2}{*}{\multicolumn{2}{|c|}{$\begin{array}{c}\text { Loma La Gloria } \\
\text { Monforte }\end{array}$}} & \multirow{3}{*}{$\begin{array}{c}\text { La Sabina } \\
\text { La Sierrita } \\
\mathrm{CG}-7 \mathrm{~b}^{a}\end{array}$} & \multirow{2}{*}{$\begin{array}{l}\text { Yaguanabo } \\
\text { Yaguanabo }\end{array}$} & \multicolumn{3}{|c|}{ El Tambor } \\
\hline & & & & & \multicolumn{2}{|c|}{ Yaguanabo } & \multirow{2}{*}{$\begin{array}{c}\text { Río Chiquito } \\
\text { SR-62 }\end{array}$} \\
\hline Muestra & SM- $82^{a}$ & SM- $82 b^{a}$ & & $\mathrm{YG}-15 \mathrm{c}^{a}$ & $7 \mathrm{CF}-8 \mathrm{~B}^{a}$ & ${\mathrm{YG}-22^{a}}^{a}$ & \\
\hline Longitud & 575574E & 575574E & $573750 \mathrm{E}$ & $583673 \mathrm{E}$ & $583525 \mathrm{E}$ & 479939E & $576654 \mathrm{E}$ \\
\hline Latitud & $238135 \mathrm{~N}$ & $238135 \mathrm{~N}$ & $240825 \mathrm{~N}$ & $230186 \mathrm{~N}$ & $229466 \mathrm{~N}$ & $338626 \mathrm{~N}$ & $236655 \mathrm{~N}$ \\
\hline Litología & $\mathrm{EC}$ & EC & EAc & EEp & EEp & EEp & EAc \\
\hline \multicolumn{8}{|c|}{ Elementos mayores (\% en peso) } \\
\hline $\mathrm{SiO}_{2}$ & 50.53 & 48.6 & 52.83 & 47.79 & 45.86 & 45.43 & 49.12 \\
\hline $\mathrm{TiO}_{2}$ & 1.28 & 1.32 & 0.34 & 1.44 & 1.37 & 1.86 & 1.53 \\
\hline $\mathrm{Al}_{2} \mathrm{O}_{3}$ & 14.9 & 15.39 & 16.66 & 20.81 & 16.61 & 15.88 & 16.12 \\
\hline $\mathrm{FeO}^{\mathrm{t}}$ & 9.74 & 9.83 & 5.03 & 6.8 & 7.48 & 10.01 & 9.68 \\
\hline $\mathrm{MnO}$ & 0.15 & 0.17 & 0.09 & 0.11 & 0.1 & 0.14 & 0.13 \\
\hline $\mathrm{MgO}$ & 7.74 & 7.66 & 8.37 & 5.61 & 4.39 & 10.35 & 7.42 \\
\hline $\mathrm{CaO}$ & 9.81 & 9.95 & 10.47 & 7.12 & 15.27 & 6.91 & 9.16 \\
\hline $\mathrm{Na}_{2} \mathrm{O}$ & 2.86 & 3.04 & 3.02 & 4.33 & 2.29 & 2.88 & 3.09 \\
\hline $\mathrm{K}_{2} \mathrm{O}$ & 0.08 & 0.08 & 0.88 & 1.2 & 0.48 & 0.66 & 0.11 \\
\hline $\mathrm{P}_{2} \mathrm{O}_{5}$ & 0.12 & 0.11 & 0.28 & 0.36 & 0.35 & 0.27 & 0.21 \\
\hline PPI & 2.09 & 2.8 & 2.86 & 3.5 & 4.95 & 4.61 & 2.77 \\
\hline Suma & 99.3 & 98.95 & 100.83 & 99.07 & 99.15 & 99 & 99.34 \\
\hline \multicolumn{8}{|c|}{ Elementos traza (ppm) } \\
\hline $\mathrm{Sc}$ & 36 & 40 & 16 & 21 & 32 & 34 & 45 \\
\hline $\mathrm{V}$ & 286 & 292 & 167 & 142 & 215 & 246 & 276 \\
\hline $\mathrm{Cr}$ & 323 & 330 & 156 & 68 & 141 & 351 & 113 \\
\hline Co & 49 & 43 & 27 & 20 & 41 & 46 & 41 \\
\hline $\mathrm{Ni}$ & 106 & 91 & 98 & 21 & 60 & 214 & 67 \\
\hline $\mathrm{Cu}$ & 56 & 51 & & 42 & 65 & & 70 \\
\hline $\mathrm{Zn}$ & 82 & 40 & 35 & 55 & 58 & 79 & 92 \\
\hline $\mathrm{Ga}$ & 16 & 16 & 11 & 15 & 15 & 15 & 17 \\
\hline $\mathrm{Rb}$ & 1.8 & 2.3 & 16 & 15 & 5.7 & 14 & 1.3 \\
\hline $\mathrm{Sr}$ & 123 & 151 & 219 & 287 & 393 & 114 & 236 \\
\hline $\mathrm{Y}$ & 31 & 33 & 8 & 23 & 24 & 27 & 28 \\
\hline $\mathrm{Zr}$ & 74 & 79 & 26 & 139 & 119 & 149 & 113 \\
\hline $\mathrm{Nb}$ & 3 & 3.4 & 2 & 27 & 28 & 23 & 13 \\
\hline Cs & 0.16 & 0.2 & & & 0.15 & 0.1 & 0.1 \\
\hline $\mathrm{Ba}$ & 101 & 299 & 63 & 221 & 52 & 50 & 47 \\
\hline $\mathrm{Hf}$ & 3.6 & 2.3 & & 3.2 & 0.36 & & 3.1 \\
\hline $\mathrm{Ta}$ & 0.41 & 0.3 & & 1.8 & 2.1 & & 0.9 \\
\hline Th & 0.28 & & & 2.5 & 2.9 & & 1.1 \\
\hline $\mathrm{U}$ & 0.04 & & & 0.8 & 0.8 & & 0.14 \\
\hline $\mathrm{La}$ & 3 & 3 & & 25 & 22 & & 10 \\
\hline $\mathrm{Ce}$ & 8.6 & 8.7 & & 50 & 42 & & 22 \\
\hline $\operatorname{Pr}$ & 1.6 & 1.6 & & 5.8 & 5 & & 3.3 \\
\hline $\mathrm{Nd}$ & 9 & 9.5 & & 24 & 21 & & 15 \\
\hline $\mathrm{Sm}$ & 3.2 & 3.1 & & 4.9 & 4.7 & & 4.2 \\
\hline $\mathrm{Eu}$ & 1.1 & 1.2 & & 1.7 & 1.6 & & 1.5 \\
\hline $\mathrm{Gd}$ & 4.7 & 4.7 & & 5.1 & 4.7 & & 5.2 \\
\hline $\mathrm{Tb}$ & 0.8 & 0.9 & & 0.8 & 0.8 & & 0.8 \\
\hline Dy & 5.4 & 5.9 & & 4.5 & 4.3 & & 5.2 \\
\hline Ho & 1.2 & 1.2 & & 1 & 0.9 & & 1.1 \\
\hline Er & 3.1 & 3.7 & & 2.8 & 2.3 & & 2.8 \\
\hline $\mathrm{Tm}$ & 0.48 & 0.5 & & 0.39 & 0.28 & & 0.39 \\
\hline $\mathrm{Yb}$ & 3 & 3.3 & & 2.4 & 1.7 & & 2.3 \\
\hline $\mathrm{Lu}$ & 0.45 & 0.5 & & 0.36 & 0.2 & & 0.3 \\
\hline
\end{tabular}

PPI = Pérdida por ignición. Litologías: EC = eclogita (resto de símbolos como en Tabla 4). 
Para efectos de comparación, se incluyeron las composiciones de rocas volcánicas y diabasas mesozoicas de la Provincia Magmática del Atlántico Central (PMAC) (Pegram, 1990; Grossman et al., 1991; Heatherington y Mueller, 1999). Este evento magmático ha sido relacionado a la apertura de Pangea y cuyo origen se debería a la acción de una pluma mantélica o como resultado del efecto de varias celdas de convección situadas bajo un ambiente de rift (Marzoli et al., 1999; McHone, 2000).

\section{Geoquímica de las rocas magmáticas y meta-magmáticas}

En las Tablas 5-7 se reporta la información geoquímica de las rocas estudiadas, que complementa a la disponible en la literatura (Cobiella-Reguera, 1996; Kerr et al., 1999; Stanik et al., 1981; Schneider et al., 2004; González y Meriño, 2005; Allibón et al., 2008). El amplio espectro composicional, aunque de características máficas $\left(\mathrm{n}=32, \% \mathrm{SiO}_{2}=39.90\right.$
- 52.8; $\% \mathrm{MgO}=3.90$ - 12.27), en elementos mayores $\left(\right.$ e.g., $\% \mathrm{Al}_{2} \mathrm{O}_{3}=12.9-20.2 ; \% \mathrm{CaO}=6.9$ $\left.-15.3 ; \% \mathrm{~K}_{2} \mathrm{O}=0.05-1.05\right)$ y traza (e.g., $\mathrm{n}=20$, $\mathrm{V}=142-451 \mathrm{ppm} ; \mathrm{Ni}=11.0-369 \mathrm{ppm} ; \mathrm{Ba}=$ $7.7-797 ; \mathrm{Zr}=26-235 \mathrm{ppm} ; \mathrm{Ce}=4.4-84 \mathrm{ppm}$; $\mathrm{Yb}=1.7-5.7 \mathrm{ppm}$ ) indica diversidad de litologías, así como los efectos de alteración y metamorfismo. La aplicación del diagrama $\mathrm{Zr} / \mathrm{Ti}-\mathrm{Nb} / \mathrm{Y}$ (Figura 5; Winchester y Floyd, 1977) confirmó un carácter máfico (aunque algunas rocas se clasifican como andesitas basálticas y andesitas), para las litologías, con una relación constante de $\mathrm{Zr} / \mathrm{Ti} \sim 0.01$. Las rocas incluidas en la Formación Jagua $(\mathrm{Nb} / \mathrm{Y}=$ 2.9) y las del Terreno Escambray (Yaguanabo-El Tambor con $\mathrm{Nb} / \mathrm{Y}=0.2-1.5)$ se reconocieron como las más máficas. Por otra parte, en el diagrama molar ACF (Figura 6) gran parte de las muestras se agruparon en un arreglo aproximadamente lineal hacia el vértice $\mathrm{FeO}^{*}$, aunque se observan algunas desviaciones hacia la posición de clorita, calcita, epidota y micas.

El análisis jerárquico de agrupamiento (Figura

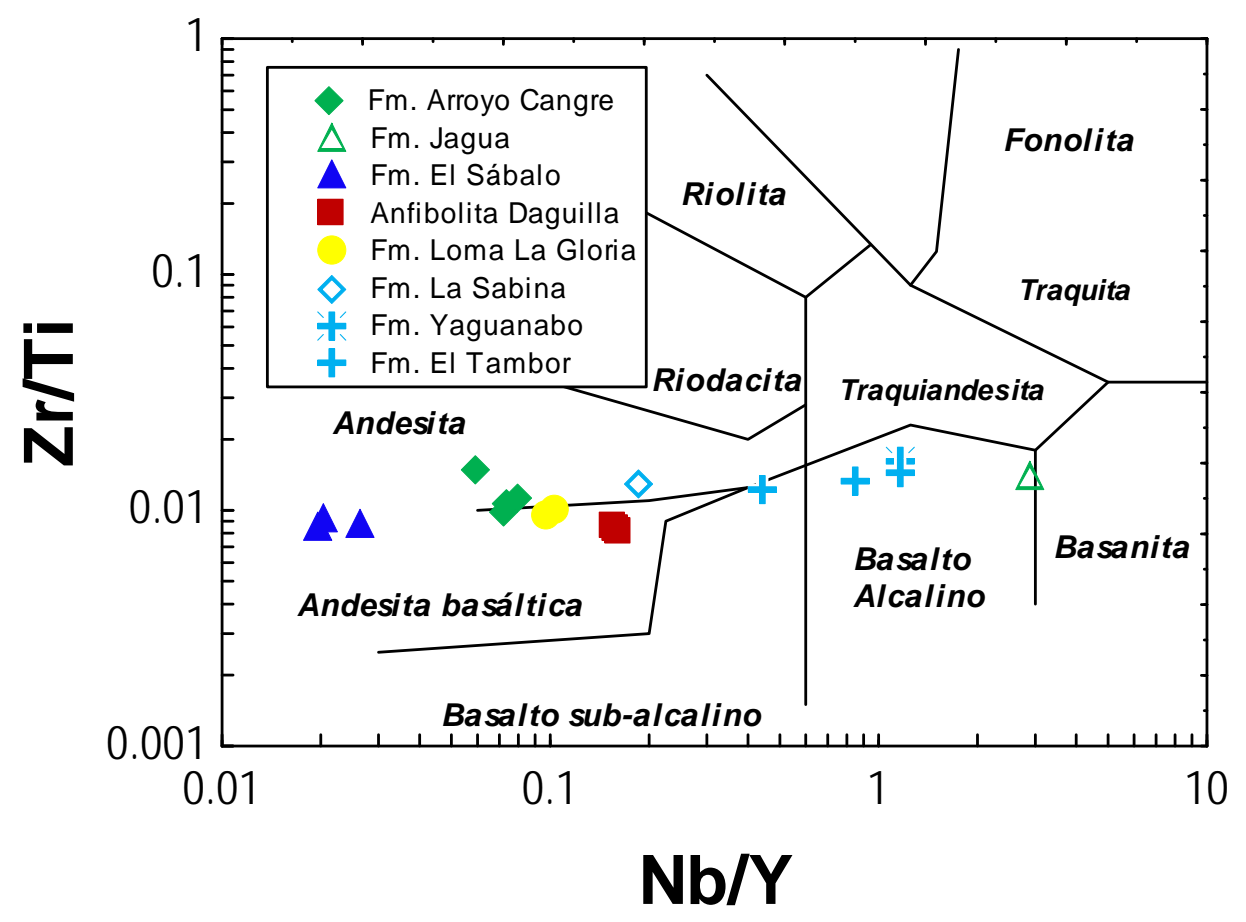

Figura 5 Diagrama Zr/Ti - Nb/Y (Winchester y Floyd, 1977), para la clasificación de rocas volcánicas alteradas, aplicado a las rocas magmáticas (Formación El Sábalo) y meta-magmáticas (resto de las formaciones) asociadas al MCP. Los datos graficados se dan en las Tablas 5-7 y se incluyen además 3 muestras de la Fm. El Sábalo (Allibón et al., 2008). 


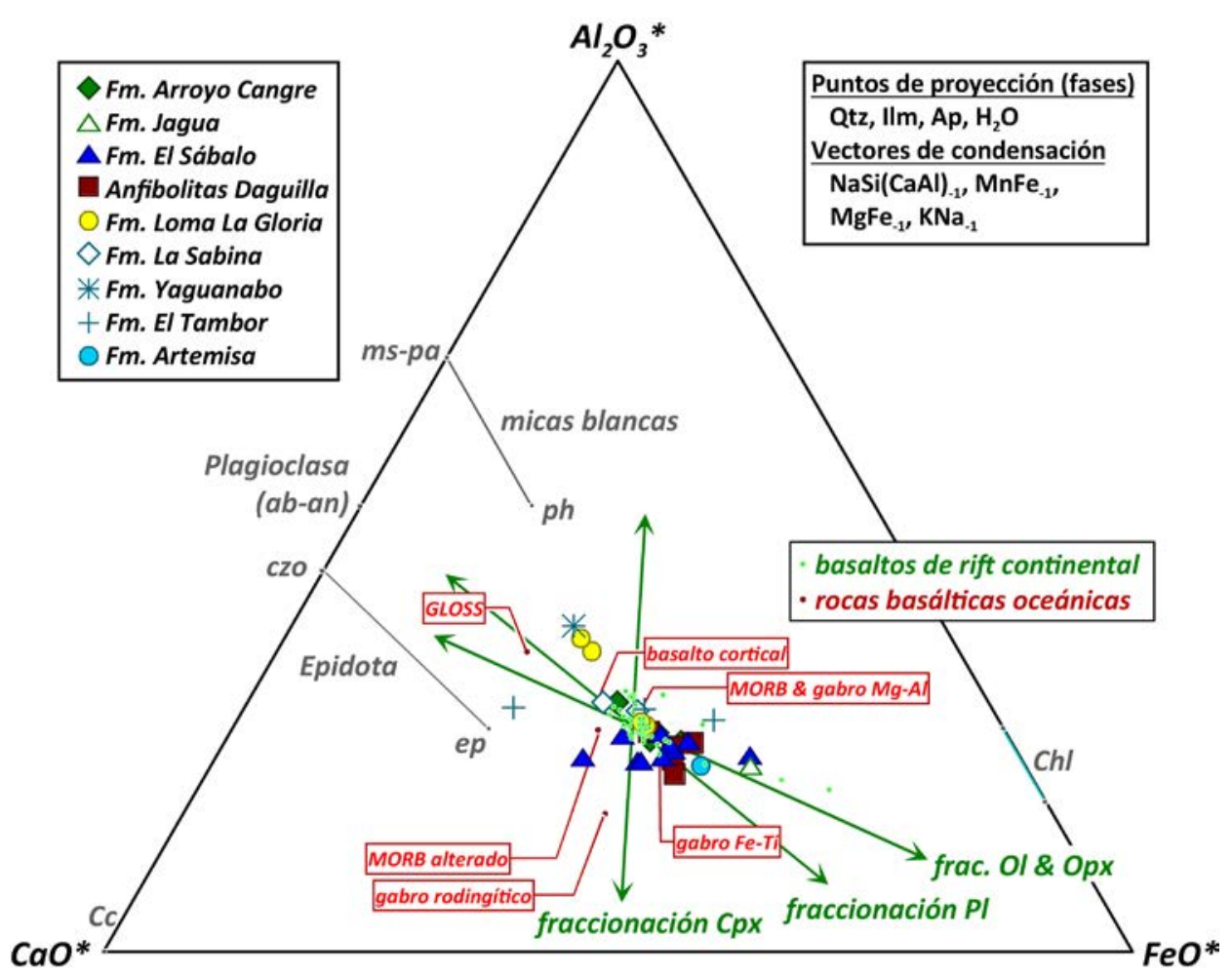

Figura 6 Diagrama triangular molar $\mathrm{Al}_{2} \mathrm{O}_{3} *-\mathrm{CaO} *-\mathrm{FeO} *$ molar o ACF proyectado desde fases y vectores de intercambio para las rocas magmáticas (formaciones El Sábalo, Artemisa y Zona Esperanza) y meta-magmáticas (resto de las formaciones) asociadas al MCP. Se incluye la proyección de MORB, GLOSS y de algunos minerales de interés, así como los vectores de cambio composicional en líquidos y acumulados esperados por efecto de la fraccionamiento de Ol- Opx, Cpx y Plg. Los datos graficados se dan en las Tablas 5-7 y, 12 muestras adicionales tomadas de otros trabajos (Stanik et al., 1981; Cobiella-Reguera, 1996; Kerr et al., 1999; Schneider et al., 2004; González y Meriño, 2005; Allibón et al., 2008). Otras rocas proyectadas como referencia son sedimentos subducidos (GLOSS; Plank y Langmuir, 1998), basalto MORB alterado (Staudigel et al., 1996), basaltos de rift continental (Dostal y Dupuy, 1984; Gottfried et al., 1983; Merle et al., 2011) y varios basaltos y gabros oceánicos (Mottana et al., 1990)

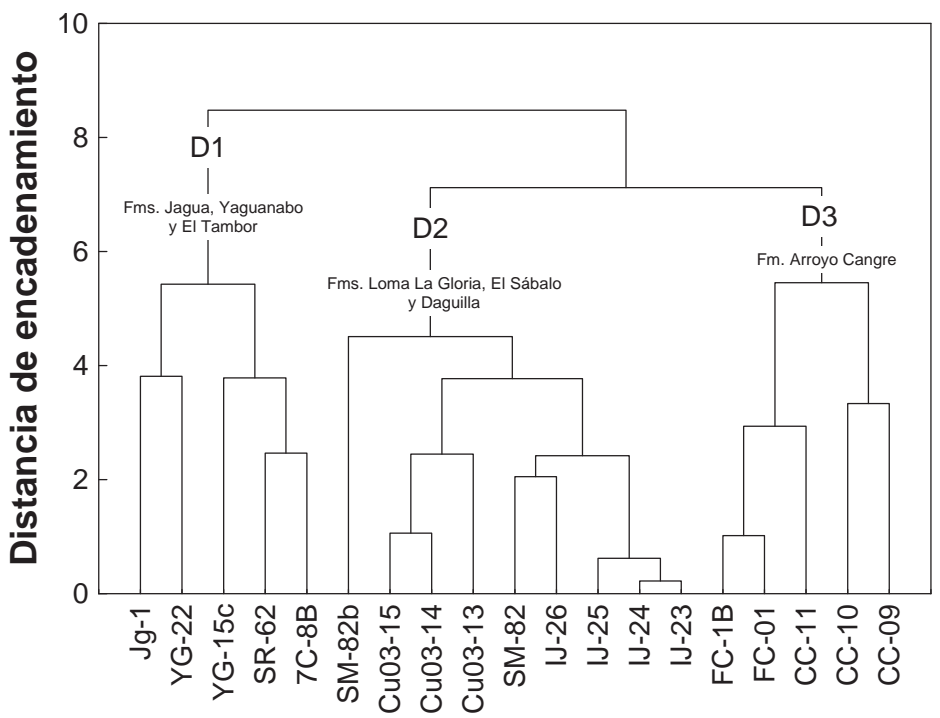

Figura 7 Dendograma que muestra los resultados del análisis jerárquico de agrupamientos (considerando distancias Eucledianas de encadenamiento; Bratchell, 1989) para las rocas magmáticas (Formación El Sábalo) y meta-magmáticas (resto de las formaciones) asociadas al MCP. Los datos graficados se dan en las Tablas 5-7 y 3 muestras de la Fm. El Sábalo (Allibón et al., 2008). 
7) permitió efectuar la distribución del conjunto de rocas estudiadas en tres dominios geoquímicos, cuyas características fueron complementadas por los patrones en diagramas normalizados multi-elementos y de lantánidos (Figuras 8-9): (a) D1 (Fagua - Yaguanabo - El Tambor): Este dominio, en el que se agrupan esquistos de epidota y actinolita complementados por el metabasalto Jg-1 ( $\mathrm{n}=$ 5), se caracteriza por ser el de composición más básica con $\% \mathrm{SiO}_{2}=48.0 \pm 3.1$ y $\% \mathrm{MgO}=8.5$ \pm 3.5. Las rocas muestran una relativa alta concentración en $\mathrm{Ni}(=146 \pm 44 \mathrm{ppm})$, así como en metales de transición de carga $+4(\mathrm{Hf}=2.8 \pm 1.7$ $\mathrm{ppm}) \mathrm{y}+5(\mathrm{Nb}=32 \pm 20 \mathrm{ppm} ; \mathrm{Ta}=2.2 \pm 1.2$ $\mathrm{ppm})$. Por otra parte, los patrones multi-elementos de las rocas de Yaguanabo y El Tambor muestran características de "zig-zag", similares a los de las muestras CU16 y LV66 de Loma La Gloria (Figura 8). En estas últimas (que no fueron consideradas en el análisis de agrupamiento, ya que no se contaba con la información química necesaria; ver Schneider et al., 2004) fue evidente además una marcada anomalía negativa de $\mathrm{Nb}$-Ta. El patrón de lantánidos de las muestras del dominio D1 son similares a las de Loma La Gloria (Figura 9), con un enriquecimiento en ligeros y un decrecimiento suave hacia medianos y pesados. De esta forma, las muestras CU16 y LV66 se han incluido en este dominio. Un caso aparte es la muestra Jg-1 de la Formación Jagua, que presenta un patrón multi-elementos altamente enriquecido en elementos incompatibles, que se asemeja a los mostrados por magmas de tipo E-MORB/OIB (MORB enriquecido en elementos incompatibles / basalto de isla oceánica). El patrón de lantánidos de esta muestra se caracteriza por un enriquecimiento en ligeros (con La en una composición 120x relativa a condrita y una relación $\mathrm{La} / \mathrm{Yb}=12 \pm 5$ ), un descenso en el contenido con el incremento del número atómico (con Lu a un nivel de 10x relativo a condrita) y la ausencia de anomalías; (b) D2 (Loma La Gloria - El Sábalo - Daguilla): En este dominio (que incluye cuerpos de anfibolita, diabasa y eclogita; $\mathrm{n}=9$ ) se encuentran los mayores espesores del magmatismo del MCP, siendo señalado por Itu-
rralde-Vinent (1996) como el pulso principal de la actividad. Su composición en elementos mayores indica características básicas con $\% \mathrm{SiO}_{2}=50.8 \pm$ 0.9 y $\% \mathrm{MgO}=7.74 \pm 0.31$. El dominio muestra, en comparación a los otros, una relativa alta concentración en Sc (44 \pm 5 ppm) y Cr (332 \pm 31 $\mathrm{ppm})$, pero un contenido restringido en elementos incompatibles (e.g., $\mathrm{Ba}=48 \pm 90 \mathrm{ppm}, \mathrm{Hf}=1.3 \pm$ $1.1 \mathrm{ppm}, \mathrm{Nb}=2.7 \pm 1.6 \mathrm{ppm}, \mathrm{Ta}=0.24 \pm 0.15$ ppm). Los patrones multi-elementos, normalizados a MORB, de El Sábalo se caracterizan por variaciones en elementos móviles $\left(\mathrm{Sr}, \mathrm{K}_{2} \mathrm{O}, \mathrm{Rb}\right.$ y $\left.\mathrm{Ba}\right)$, una anomalía negativa de $\mathrm{Nb}$ y un enriquecimiento en $\mathrm{P}_{2} \mathrm{O}_{5}$. En contraste, los patrones multi-elementos de la Anfibolita Daguilla (IJ-23 a IJ-26) y de Loma La Gloria (muestras SM-82 y SM-82b) son suavemente cóncavos, con una ocasional anomalía negativa (IJ-26) y positiva (SM-82b) de $\mathrm{Ba}$ (Figura 8). Los patrones de lantánidos para este dominio se distinguen por un empobrecimiento en ligeros (relación $\mathrm{La} / \mathrm{Yb}=0.86 \pm 0.35$ ), la ausencia de anomalías y un arreglo cuasi-horizontal para elementos medianos y pesados con una concentración de $\sim 10$ x en relación a condrita (Figura 9). Es importante señalar que el grupo $D 2$ contrasta en sus patrones multi-elementos y de lantánidos con los que caracterizan a las muestras CU16 y LV66 (Figuras 8D y 9D; Loma La Gloria; Schneider et al., 2004), que se han considerado parte del grupo D1; (c) D3 (Arroyo Cangre): El dominio está conformado por metagabros anfibolizados con $\% \mathrm{SiO}_{2}$ $=49.6 \pm 1.4$ y $\% \mathrm{MgO}=6.7 \pm 0.6(\mathrm{n}=5) . \mathrm{En}$ comparación a los otros dominios, los metagabros muestran un contenido relativamente bajo en $\mathrm{Ni}$ $(50 \pm 10 \mathrm{ppm})$ y alto en litófilos $(\mathrm{Rb}=17 \pm 11$ ppm, $\mathrm{Sr}=230 \pm 70 \mathrm{ppm})$. Los patrones multi-elementos se caracterizan por tender a ser horizontales, aunque en algunos casos con desviaciones positivas de elementos litófilos de gran movilidad en condiciones de alteración $\left(\mathrm{K}_{2} \mathrm{O}, \mathrm{Rb}, \mathrm{Ba}\right)$. Sus patrones de lantánidos también muestran una tendencia horizontal (relación La/Yb $=1.30 \pm 0.05$ ), sin evidencia de anomalías y con una concentración elemental $\sim 35 \mathrm{x}$ con respecto a condrita.

Por otra parte, una serie de diagramas de varia- 

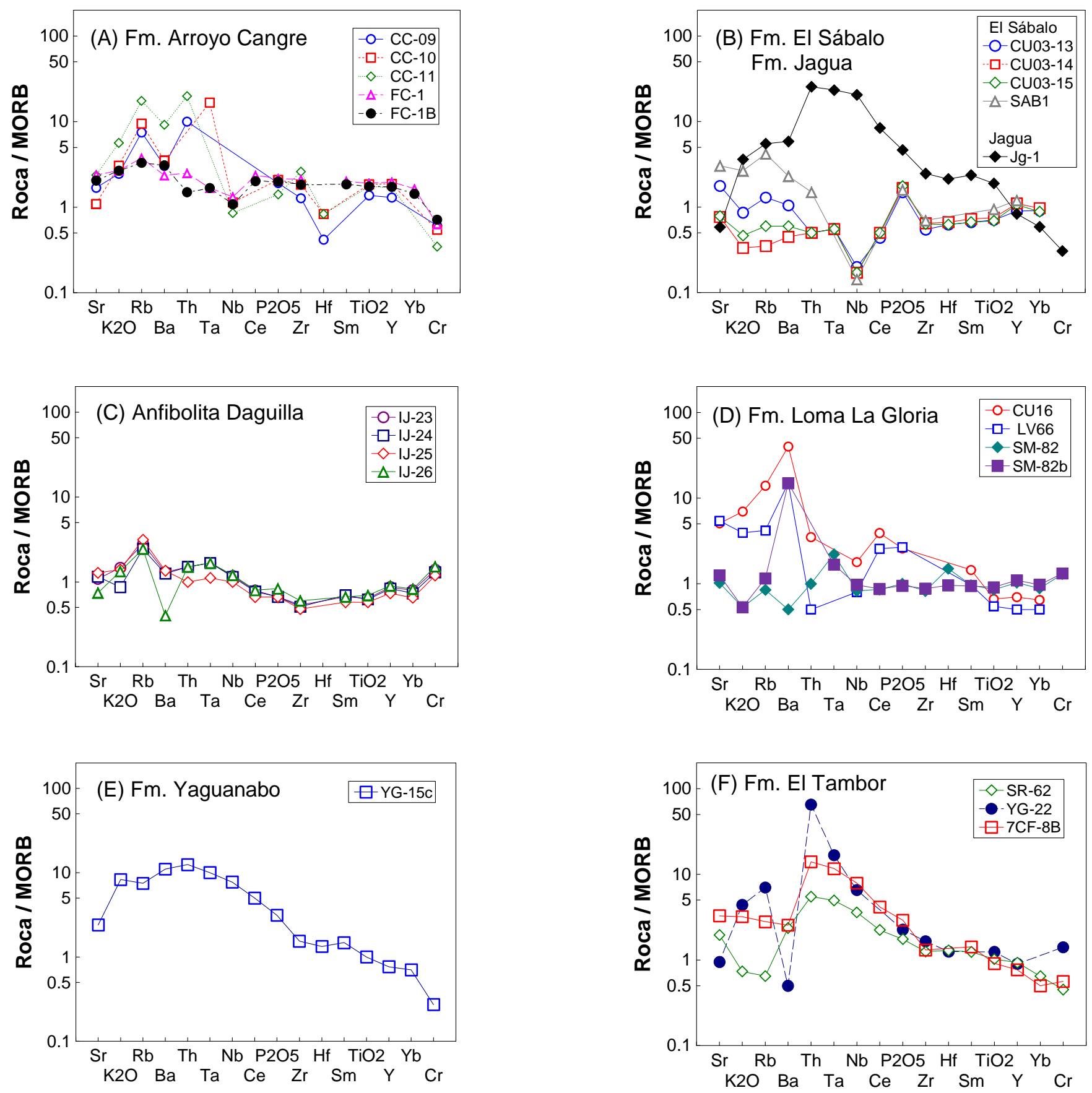

Figura 8 Diagramas multi-elementos normalizados a MORB para rocas magmáticas y meta-magmáticas asociadas al MCP: (A) Formación Arroyo Cangre; (B) Formación El Sábalo / Formación Jagua; (C) Anfibolita Daguilla; (D) Formación Loma La Gloria; (E) Formación Yaguanabo; (F) Formación El Tambor. Valores de normalización (\%peso para óxidos mayores y ppm para elementos traza) de Pearce (1982): $\mathrm{Sr}=120, \mathrm{~K}_{2} \mathrm{O}=0.15, \mathrm{Rb}=2, \mathrm{Ba}=20, \mathrm{Th}=0.20, \mathrm{Ta}=0.18, \mathrm{Nb}=3.5, \mathrm{Ce}=10, \mathrm{P2O}=0.12, \mathrm{Zr}=90, \mathrm{Hf}=2.40, \mathrm{Sm}=$ $3.3, \mathrm{TiO}_{2}=1.5, \mathrm{Y}=30, \mathrm{Yb}=3.4, \mathrm{Cr}=250$. Los datos graficados se dan en las Tablas 5-7; además se incluyen: 4 muestras de la Fm. El Sábalo (Kerr et al., 1999; Allibón et al., 2008) y 2 de la Fm. Loma La Gloria (Schneider et al., 2004). 

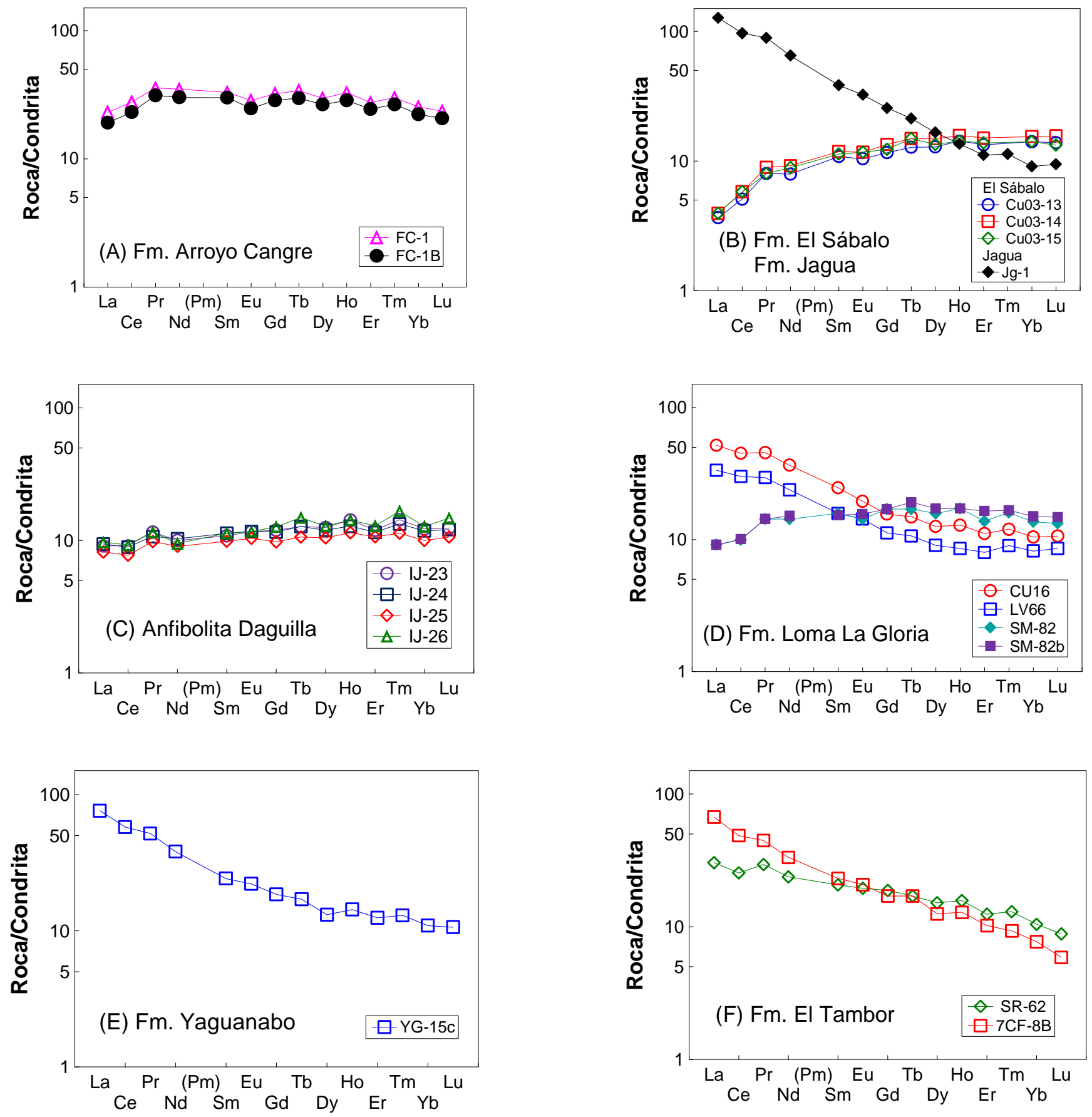

Figura 9 Diagramas de lantánidos normalizados a condrita para rocas magmáticas y meta-magmáticas asociadas al MCP: (A) Formación Arroyo Cangre; (B) Formación El Sábalo / Formación Jagua; (C) Anfibolita Daguilla; (D) Formación Loma La Gloria; (E) Formación Yaguanabo; (F) Formación El Tambor. Valores de normalización (ppm) de Haskin et al. (1968) y Nakamura $(1974)$ : La = 0.329, Ce = $0.865, \mathrm{Pr}=0.112, \mathrm{Nd}=0.63, \mathrm{Sm}=0.203, \mathrm{Gd}=0.276, \mathrm{~Tb}=0.047, \mathrm{Dy}=0.343, \mathrm{Ho}=0.07, \mathrm{Er}=0.225, \mathrm{Tm}=0.03, \mathrm{Yb}=0.22, \mathrm{Lu}=0.0339$. Los datos graficados se dan en las Tablas 5-7; además se incluyen: 3 muestras de la Fm. El Sábalo (Allibón et al., 2008) y 2 de la Fm. Loma La Gloria (Schneider et al., 2004). 
ción, que involucran elementos mayores y traza, se utilizaron para inferir la afinidad tectónica de las litologías bajo estudio. Estos diagramas incluyeron, para efectos de comparación, campos obtenidos de rocas de la PMAC. Por ejemplo, en el diagrama $\mathrm{Nb} / \mathrm{Y}-\mathrm{Ba} / \mathrm{Nb}$ (Figura 10), la mayor parte de las rocas de los dominios $D 2$ y $D 3$ presentan composiciones que asemejan a las tipo N-MORB. El desplazamiento de algunas litologías de La Sabina, Arroyo Cangre y Loma La Gloria, hacia valores de $\mathrm{Ba} / \mathrm{Nb}>40$, pudiera estar asociado a procesos de asimilación de sedimentos. Por otra parte, las muestras del dominio $D 1$ se distribuyen en un arreglo lineal (con una relación $\mathrm{Ba} / \mathrm{Nb}$ aproximadamente constante) entre las composiciones tipo MORB y OIB, lo que reflejaría variaciones de enriquecimiento de elementos incompatibles en la fuente de Manto (tipo E-MORB) o de las condiciones en las que ocurre la fusión parcial, tendencia también observada para las rocas del PMAC (Figura 10).

En el espacio $\mathrm{Th} / \mathrm{Yb}-\mathrm{Nb} / \mathrm{Yb}$ (Figura 11), las

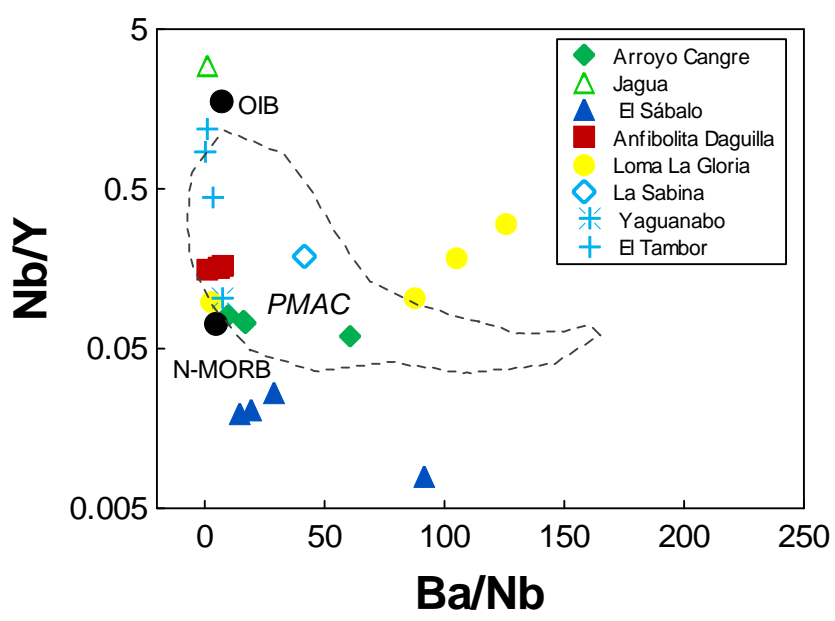

Figura 10 Diagrama de variación $\mathrm{Nb} / \mathrm{Y}-\mathrm{Ba} / \mathrm{Nb}$ para rocas magmáticas (Formación El Sábalo) y meta-magmáticas (resto de las formaciones) asociadas al MCP. Los datos graficados se dan en las Tablas 5-7; además se incluyen: 4 muestras de la Fm. El Sábalo (Kerr et al., 1999; Allibón et al., 2008) y 2 de la Fm. Loma La Gloria (Schneider et al., 2004). Para fines de comparación, se dan las relaciones correspondientes a basaltos promedio de tipo N-MORB y OIB (Rollinson, 1993) y el campo que ocupan las rocas pertenecientes a la Provincia Magmática del Atlántico Central ( $n=445)$. Ver Figura 7 para visualizar los correspondientes dominios $(D)$ de cada Formación. muestras bajo estudio se distribuyen a través del arreglo lineal tipo N-MORB/E-MORB/OIB. Las muestras incluidas en el dominio $D 1$ se caracterizan por mostrar relaciones $\mathrm{Nb} / \mathrm{Yb}>4$ y $\mathrm{Th} /$ $\mathrm{Yb}>0.5$ que son comparables a las observadas en E-MORB. El metabasalto de Jagua Jg-1 se proyecta hacia la región de una fuente mantélica más enriquecida tipo OIB. Por su parte, las muestras de los dominios $D 2$ y $D 3$ se asemejan a N-MORB, con relaciones $\mathrm{Nb} / \mathrm{Yb} \leq 4$ y $\mathrm{Th} / \mathrm{Yb}<0.5$. La naturaleza toleítica $(\mathrm{Nb} / \mathrm{Yb}<20)$ de las rocas y su asociación a características parecidas a N-MORB o E-MORB $\left(\mathrm{TiO}_{2} / \mathrm{Yb}<1\right)$, con excepción de la muestra Jg-1 (Jagua), también fue confirmado en el diagrama $\mathrm{TiO} 2 / \mathrm{Yb}$ - Nb/Yb (Figura 12). En ambas figuras, existe una similitud entre las litologías estudiadas y los campos que marcan las rocas de la PMAC. Por otra parte, Marzoli et al., (1999) y McHone (2000) han reportado que la mayor parte de este evento magmático consiste de basaltos toleíticos de $\% \mathrm{SiO}_{2}=46-49$ y $\mathrm{TiO}_{2}<2 \%$, y con enriquecimientos moderados a marcados en lan-

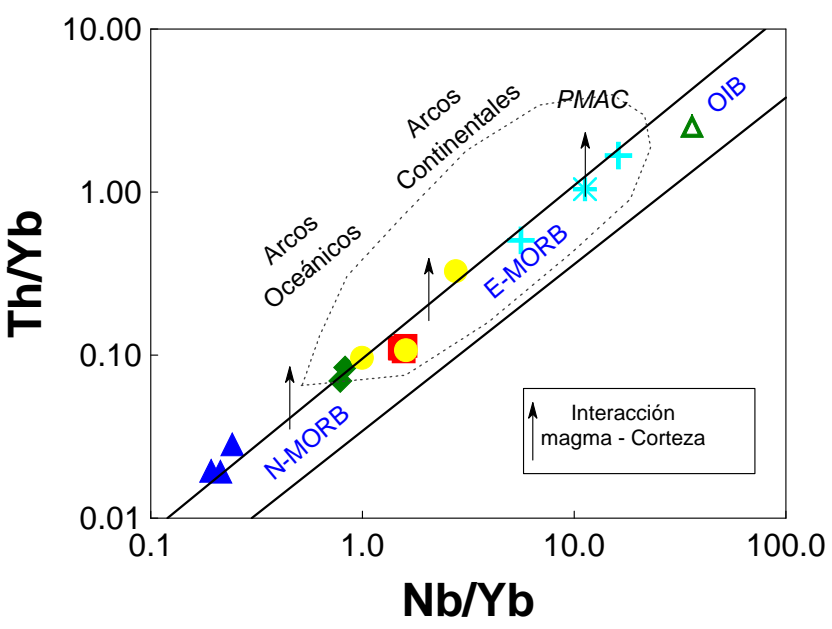

Figura 11 Diagrama de variación Nb/Yb - Th/Yb (Pearce, 2008) para rocas magmáticas (Formación El Sábalo) y metamagmáticas (resto de las formaciones) del MCP. Los datos incluidos en la gráfica se reportan en las Tablas 5-7; además se incluyen: 3 muestras de la Fm. El Sábalo (Allibón et al., 2008) y 2 de la Fm. Loma La Gloria (Schneider et al., 2004). Se dan las zonas del diagrama en donde se ubicarían los arreglos MORBOIB y el campo que marca las rocas pertenecientes a la Provincia Magmática del Atlántico Central $(n=445)$. Ver Figura 7 para visualizar los correspondientes dominios $(D)$ de cada Formación. Símbolos como en la Figura 10. 


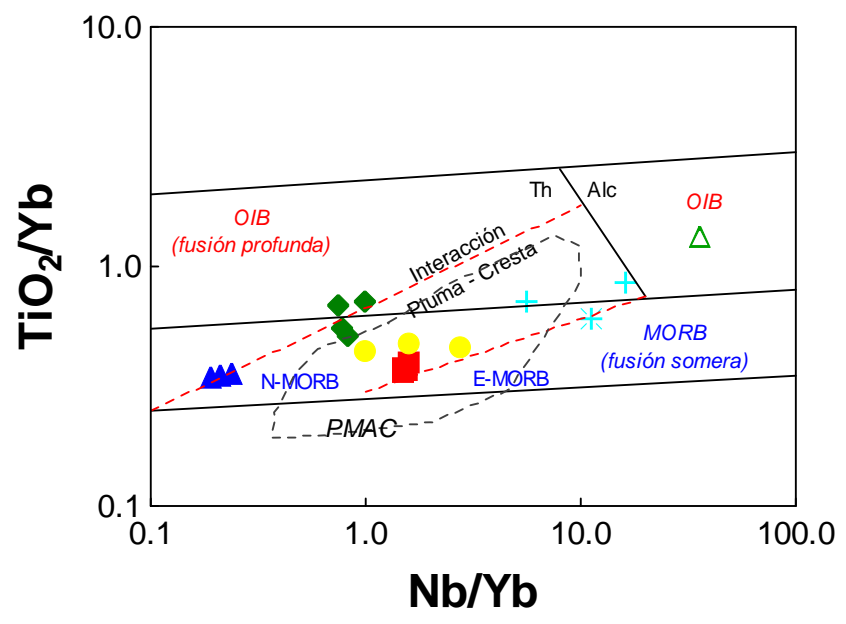

Figura 12 Diagrama de variación $\mathrm{TiO}_{2} / \mathrm{Yb}-\mathrm{Nb} / \mathrm{Yb}$ (Pearce, 2014) para rocas magmáticas (Formación El Sábalo) y meta-magmáticas (resto de las formaciones) del MCP. Los datos graficados son los mismos de la figura anterior. Se incluyen las zonas en donde se ubicarían los productos de fusión somera (MORB) o profunda (OIB) del Manto. Th = rocas toleíticas, Alc = rocas alcalinas; así como, el campo que marca las rocas pertenecientes a la Provincia Magmática del Atlántico Central $(n=445)$. Ver Figura 7 para visualizar los correspondientes dominios $(D)$ de cada Formación. Símbolos como en la Figura 10.

tánidos ligeros con respecto a pesados. Su origen se ha asociado a varias celdas de convección que actuaron bajo un ambiente de rift que fue evolucionando a una cresta oceánica. Cabe aclarar que, aunque las muestras de la Formación El Sábalo se ubican fuera del campo PMAC, presentan características geoquímicas similares $\left(\% \mathrm{SiO}_{2}=48.2\right.$ 50.0 y $\mathrm{TiO}_{2}=1.04-1.13 \%$; Allibon et al., 2008). Finalmente, la aplicación de un diagrama de discriminación tectónica de funciones multi-dimensionales (Figura 13), consistentes del logaritmo de relaciones de elementos mayores (Verma et al., 2006), confirmó características tipo MORB para la mayor parte de las muestras bajo estudio (con un $99 \%$ de nivel confianza). Como se observó en otros diagramas de variación, algunas muestras del dominio D1 (especialmente Jagua) muestran una afinidad similar a una fuente de tipo OIB, que en este caso podría considerarse comparable a E-MORB.

\section{Discusión}

El estudio del magmatismo es una pieza fundamental para entender la evolución geológica de Cuba y de la región del Caribe. Sin embargo, la información disponible sobre las litologías magmáticas y meta-magmáticas que ocurren dentro de las secuencias siliciclásticas y carbonatadas del Margen Continental Pasivo (Jurásico Inferior?Cretácico Superior basal; Figura 3) es relativamente escasa y dispersa. En ocasiones, estas rocas fueron confundidas con aquellas relacionadas con subducción o se les consideró con un origen incierto, hasta que Iturralde-Vinent (1988b) las refiere como de margen continental. En el caso del magmatismo básico de Arroyo Cangre (Cordillera de Guaniguanico; Figura 2) se ha indicado que: (a) está relacionado a un fracturamiento profundo ligado al desarrollo inicial de un geosinclinal (Piotrowski, 1977); (b) se origina en un sistema de fosas

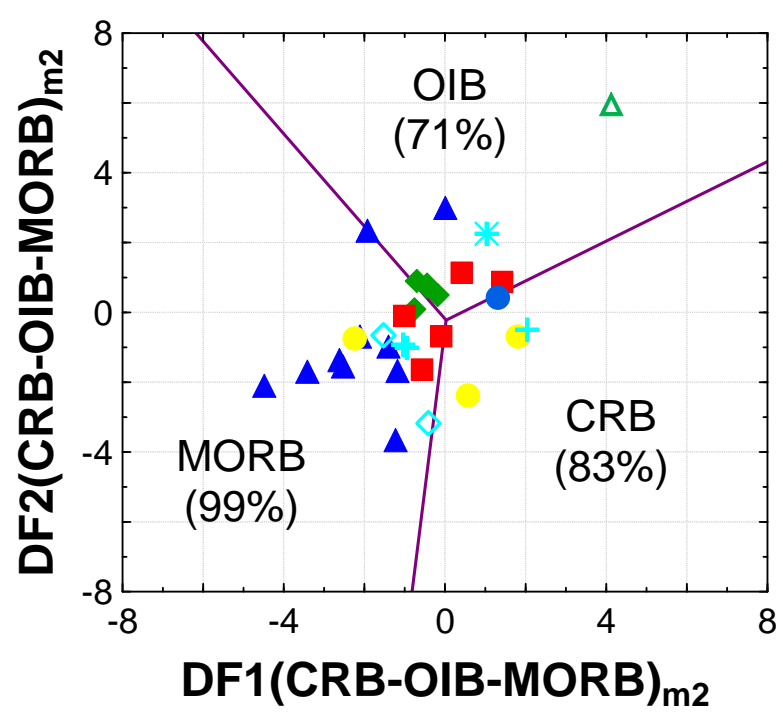

Figura 13 Diagrama de discriminación tectónica de funciones multi-dimensionales, dependientes del logaritmo de relaciones de elementos mayores (Verma et al., 2006), para rocas magmáticas (formaciones El Sábalo, Artemisa y Zona Esperanza) y meta-magmáticas (resto de las formaciones) del MCP. MORB = basaltos de cresta oceánica, OIB = basaltos de isla oceánica, CRB = basaltos de rift continental. Los símbolos corresponden como en la Figura 6, así como los datos ploteados. 
profundas en el interior de la placa Norteamericana (Shein y Kleschov, 1985); (d) representa un magmatismo primitivo de un arco jurásico (Martínez et al., 1987), idea poco aceptada; (e) que estas rocas de Arroyo Cangre, así como las observadas en los terrenos Pinos, Escambray y Asunción, eran el producto de la riftogénesis ligada al rompimiento y dispersión de Pangea (Iturralde-Vinent, 1988b), que derivó, entre otros, con la apertura del mar Caribe primitivo o proto-Caribe. Por otra parte, Pindell y Kennan (2009) ubicaron la apertura riftogenética en el borde sureste de los bloques Yucatán y Chortis hace 190 Ma y señalaron además un desarrollo franco de corteza oceánica a los 140 Ma. También Cobiella-Reguera (1996) distinguió tres épocas de actividad magmática para la región del Caribe, relacionadas con la fragmentación de Pangea: (1) finales del Triásico y el Jurásico Inferior, la cual no está representada en Cuba, (2) durante el Oxfordiano, que fue la de mayor desarrollo en Cuba y vinculada además con un cambio en la sedimentación de terrígena a carbonatada, y (3) en el intervalo Tithoniano - Cretácico Inferior. Por lo antes expuesto, era de esperar que el magmatismo y sus derivados metamorfizados incluidos en el MCP cubano estudiado evidenciaran características tipo N-MORB, acompañada de una tendencia hacia tipo E-MORB. El análisis de la base de datos petrográfica y química, en el presente estudio, permitió confirmar esta diversidad litológica y evaluar las hipótesis propuestas para explicar su origen.

En primer lugar, aún teniendo en cuenta el efecto de la alteración superficial y/o el metamorfismo/ metasomatismo y/o la eventual asimilación de corteza continental durante el ascenso y emplazamiento de los magmas, cabe destacar un carácter máfico para $\sim 86 \%$ de las muestras con una composición en $\% \mathrm{SiO}_{2}=43-51$ y de $\% \mathrm{MgO}=6$ - 12 (Tablas 5-7). Se ha señalado que los basaltos tipo $\mathrm{MORB}$ con $\% \mathrm{SiO}_{2}<50$ y $\% \mathrm{MgO}>9.5 \%$ tienen características primitivas y una derivación directa desde el manto superior por fusión parcial (Floyd, 1991). En el caso de las rocas bajo estudio, es posible considerar una condición cercana a la primitiva y en donde la disminución de $\% \mathrm{MgO}$ a un valor de $\sim 6$ podría ser explicable en términos de fraccionamiento de minerales ferromagnesianos.

De acuerdo al diagrama ACF (Figura 6), los líquidos magmáticos podrían haber experimentado un proceso de cristalización controlado fundamentalmente por plagioclasa y piroxeno/olivino. Las desviaciones observadas a este arreglo pudieran ser resultado de: (a) metasomatismo (alteración hacia clorita, muestra YG-22 [El Tambor], y/o calcita y/o epidota, muestras 7CF-8B [El Tambor] y 9 [Zona Esperanza]) o (b) la asimilación de micas detríticas (muestras LV66 y CU16 [Loma La Gloria], YG-15c [Yaguanabo]) durante la intrusión de los magmas en la secuencia sedimentaria. Cabe señalar que Allibon et al. (2008) reportaron que las diabasas El Sábalo no presentan una correlación entre las relaciones isotópicas ${ }^{87} \mathrm{Sr} /{ }^{86} \mathrm{Sr}$ $(0.7047-0.7073, \mathrm{n}=3)$ y ${ }^{143} \mathrm{Nd} /{ }^{144} \mathrm{Nd}(0.513176$ $-0.513191, \mathrm{n}=3$ ), quedando además fuera del denominado "Arreglo del Manto" (Rollinson, 1993). Esto fue interpretado como resultado del metamorfismo de bajo grado y/o los efectos de alteración asociados. De esta forma, estos dos fenómenos, junto con un metamorfismo de mayor grado y/o los procesos de retrogresión post pico metamórfico (Despaigne-Díaz, 2009) que afectaron algunas de las muestras, serían los responsables de la presencia de algunos de los arreglos minerales y geoquímicos observados (Tabla 4; Figura 6). Es fundamental considerar que, estos fenómenos de metamorfismo/alteración debieron dar lugar a importantes variaciones en la geoquímica original de las rocas, lo que dificulta la interpretación sobre el origen y la afinidad tectónica de las rocas bajo estudio. Por ejemplo, Schneider et al. (2004), quienes no tomaron en cuenta ésta situación, relacionaron las eclogitas de Loma La Gloria (muestras CU16, LV66) con magmatismo de arco volcánico, algo claramente disputable en base a las características geológicas de estas rocas, intercaladas en series sedimentarias de margen continental pasivo que no muestran evidencia alguna de haber sido depositadas en una cuenca de suprasubducción 
durante el Jurásico.

De acuerdo a los criterios anteriormente mencionados, el contraste geoquímico entre las litologías magmáticas y metamagmáticas, así como su posición en las unidades litoestratigráficas, se puede proponer que el magmatismo del MCP ocurrió en tres etapas (Figura 14).

A) MAGMATISMO DERIVADO DE UNA FUENTE TIPO E-MORB (JURÁSICO INFERIOR? - JURÁSICO SUPERIOR/ OXFORDIANO MEDIO-SUPERIOR):

Aquí se incluyen las muestras de la Formación Jagua (dominio D1) y las muestras CU16 y LV66 de la Formación Loma La Gloria (Figuras 8-9). La mayor parte muestran una composición comparable a las rocas de la PMAC (Figuras 10-12) y podrían representar magmas derivados de una fuente de Manto más enriquecida en elementos incompatibles tipo E-MORB. Es importante señalar que, el magmatismo bajo estudio se generó asociado a una condición de rompimiento continental que evolucionó en un modelo rift-drift en sedimentos detríticos y marinos de aguas poco profundas (cuenca San Cayetano; Figura 14). En esta condición, aún no se había establecido un régimen de dispersión continental en estado estacionario y, sin la influencia de una extensión asociada a un pluma de Manto, debería ocurrir la generación de basaltos tipo E-MORB desde un Manto subcontinental enriquecido. Este proceso fue caracterizado por Pearce (2014; ver Figura 1C de ese trabajo) en condiciones de Margen Continental y pudo haber ocurrido con un grado de fusión relativamente bajo, dando lugar a basaltos MORB altamente enriquecidos en elementos incompatibles.

\section{B) MAGMATISMO DERIVADO DE UNA FUENTE TIPO N-MORB (JURÁSICO SUPERIOR/OXFORDIANO SUPERIOR - CRETÁCICO INFERIOR):}

De acuerdo a los diagramas normalizados (Figuras 8-9) y de variación (Figuras 10-13), la mayor parte de las muestras de los dominios D2 (formaciones Loma La Gloria, El Sábalo y Anfibolitas Daguilla) y D3 (Formación Arroyo Cangre), así como la Formación La Sabina (por su ubicación en las Figuras 6 y 10 con algunas rocas de estos dominios), presentan características semejantes a N-MORB y se asemejan a la geoquímica que caracteriza a las rocas de la PMAC, magma generado durante el desarrollo de la corteza oceánica proto-Caribe (Figura 14). Cabe señalar que algunas relaciones índice de elementos traza, por ejemplo, $\mathrm{Dy} / \mathrm{Yb}<$ 2.0 (con excepción de CG-10) o la relación $\mathrm{TiO}_{2}$ / $\mathrm{Yb}<1.0$ también confirman la importancia de un proceso de fusión de una fuente somera de Manto ( $\sim 60 \mathrm{~km})$, la cual se podría haber fundido hasta en un $\sim 20 \%$ (Pearce, 2014). Las relaciones isotópicas de ${ }^{143} \mathrm{Nd} /{ }^{144} \mathrm{Nd}$ para las diabasas El Sábalo (Allibon et al., 2008) corresponden a un Manto empobrecido. Las desviaciones en composición geoquímica observadas en las rocas $D 2$ y $D 3$, con respecto a MORB, podrían estar relacionadas a la asimilación de material siliciclástico, alteración superficial y evolución metamórfica de las correspondientes a los terrenos Pinos y Escambray (Figura 6). Además, se ha reportado que la alteración marina a baja temperatura $\left(<50^{\circ} \mathrm{C}\right)$ o un metamorfismo en facies de esquistos verdes del MORB puede dar lugar a la movilidad de elementos litófilos (Cs, Rb, Ba; Jochum y Verma, 1996). En el caso particular de la Formación Loma La Gloria, la actividad se inició como E-MORB (como se señaló en el dominio D1), pero con la evolución del margen esta secuencia siliciclástica fue penetrada, en esta etapa, por N-MORB. Por una posición estratigráfica comparable con la Formación Loma La Gloria, esta hipótesis también podría ser aplicable para el caso de la Formación Arroyo Cangre (Figura 3).

C) MAGMATISMO DERIVADO DE UNA FUENTE TIPO E-MORB (CRETÁCICO INFERIOR TARDÍO - CRETÁCICO SUPERIOR BASAL):

En esta fase se incluyen los esquistos de epidota y actinolita del dominio D1 (formaciones Yaguanabo y El Tambor), que se identifican con las rocas E-MORB de la PMAC (Figura 11). Este magmatismo parece haber evolucionado en sedimentos marinos de aguas profundas (Figura 3 y Tabla 3) en el transcurso de la apertura oceánica. Bajo estas condiciones posiblemente el prisma sedimentario tipo margen pasivo de Caribeana se localizó en 

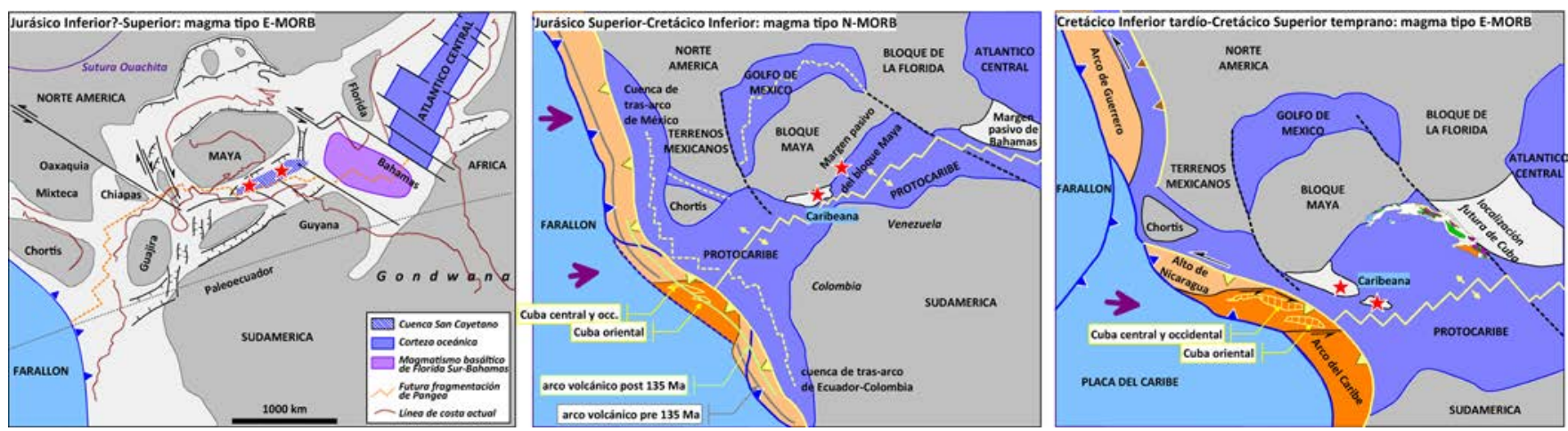

Figura 14 Reconstrucción paleotectónica de la región del Caribe para el Jurásico-Cretácico (según Pindell y Kennan, 2009; Pindell et al., 2012; véase también Rojas-Agramonte et al., 2008, 2016) con indicación del magmatismo de Margen Continental Pasivo, actualmente expuesto en el occidente y centro de Cuba. La ruptura de Pangea en el Jurásico Inferior-Medio dio lugar a magmatismo tipo E-MORB en cuencas intracontinentales (e.g., San Cayetano) que evolucionó a magmatismo (estrella roja) tipo N-MORB (Oxfordiano- Cretácico Inferior) cuando se desarrolló la corteza oceánica del proto-Caribe, conectado con el Atlántico Central. Con el transcurso de la apertura oceánica durante el Cretácico Inferior-Superior el prisma sedimentario tipo margen pasivo de Caribeana se localizó en una posición peninsular, al igual que el margen pasivo de Bahamas. En este contexto se generó magmatismo de margen pasivo tipo E-MORB. En la figura del extremo derecho se indica la localización futura (Cretácico tardío- Paleoceno) del arco volcánico del Caribe en Cuba tras su colisión con los márgenes pasivos del bloque Maya y Bahamas.

una posición peninsular (Figura 14) propiciando la generación de este magma. El proceso pudo igualmente haber ocurrido con un grado de fusión relativamente bajo, dando lugar a basaltos MORB altamente enriquecidos en elementos incompatibles. También Giunta et al. (2006) reportaron algunos episodios de plumas de manto durante el desarrollo de la corteza oceánica del proto-Caribe. Cabe aclarar que este magmatismo tipo E-MORB sólo se desarrolló en el Terreno Escambray.

\section{Conclusiones}

Durante el proceso de rompimiento de Pangea, en los márgenes de Yucatán (Maya), Chortis y América del Sur, se dieron condiciones para el desarrollo de una intensa actividad magmática. En el caso del occidente y centro de Cuba, este magmatismo se asoció con secuencias siliciclásticas y carbonatadas, que constituyeron un Margen Continental Pasivo vinculado al Bloque Maya.

De acuerdo a la información disponible (y considerando la escasez de datos paleontológicos), es dificil establecer con precisión la evolución en el tiempo de este magmatismo. Las secuencias en las que ocurre están fragmentadas y fueron deformadas durante la colisión arco-continente del Cretácico Superior-Eoceno Medio (Iturralde-Vinent, 1998; García-Casco et al., 2008).

Sin embargo, la actividad magmática probablemente se inició de forma simultánea a la sedimentación de terrígenos y carbonatos de aguas someras (Jurásico Inferior? - Jurásico Superior/ Oxfordiano Medio-Superior) y tuvo características tipo E-MORB (algunas litologías de las formaciones Loma La Gloria y Jagua). Su génesis estaría ligada a un proceso de fusión parcial de una fuente mantélica enriquecida.

Posteriormente, durante el proceso de extensión del margen continental o durante el inicio del proceso de dispersión oceánica en estado estacionario, la actividad magmática cambió a características N-MORB (e.g., litologías incluidas en las formaciones Arroyo Cangre, algunas en Loma La Gloria, El Sábalo y las Anfibolitas Daguilla). Su generación estuvo asociada a una fusión parcial de una fuente mantélica empobrecida. El evento N-MORB se desarrolló durante el Jurásico Superior/Oxfordiano Superior - Cretácico Inferior, siendo el pulso principal de actividad, representado por los cuerpos de la Formación El Sábalo y la 
Anfibolita Daguilla que se alojaron en los siliciclásticos del MCP (e.g., formaciones Arroyo Cangre y Loma La Gloria).

Un magmatismo tipo E-MORB se registra nuevamente en el Cretácico Inferior tardío - Cretácico Superior basal (litologías de las formaciones Yaguanabo y El Tambor). Sin embargo, éste se ha interpretado vincuado a un prisma sedimentario tipo margen pasivo de Caribeana. La actividad magmática concluyó a principios del Cretácico Superior, al tiempo que tuvo lugar una sedimentación de carbonatos pelágicos y silicitas asociada a subsidencia del margen continental y la dispersión continental.

La mayoría de estas secuencias sedimentarias y el magmatismo asociado de los terrenos Pinos y Escambray fueron metamorfizadas durante la subducción de Caribeana en el Campaniano Superior y, posteriormente, exhumadas en el periodo Maastrichtiano - Paleoceno temprano (García-Casco et al., 2008).

\section{Agradecimientos}

Los autores agradecen a sus instituciones sedes y a aquellas en las que se efectuaron los análisis químicos de las rocas bajo estudio. Asimismo, se agradecen los oportunos comentarios de los Drs. Jorge L. Cobiella-Reguera, Manuel Iturralde Vinent y Yamirka Rojas Agramonte, quienes permitieron mejorar la calidad del manuscrito. Finalmente, los autores reconocen la labor del Dr. Joaquín A. Proenza Fernández como editor de este manuscrito. El artículo es una contribución al proyecto "Evolución Geodinámica (Paleogeográfica) de Cuba occidental y central entre el Jurásico Tardío y el Plioceno" del Departamento de Geología, Universidad de Pinar del Río (Cuba) y al proyecto CGL2009-12446 (MINECO, España).

\section{Referencias}

Allibon, J., Lapierre, H., Bussy, F., Tardy, M., Cruz-Gámez, E.M., Senebier, F., 2008, Late Jurassic continental flood basalt doleritic dykes in northwestern Cuba: remnants of the Gulf of Mexico opening: Bulletin Sociéte Géologique France, 179, 445-452.

Álvarez-Sánchez, H., Millán-Trujillo, G., Mainegra, V., Bernal-Rodríguez, L.R., Ando, J., 1991, Significado geotectónico de las rocas eclogíticas de Cuba central, Décimo tercera Conferencia Geológica del Caribe, Pinar del Río, Guba, Sociedad Cubana de Geología, 28-29.

Babushkin, V.N., 1990, Informe de los trabajos del levantamiento geológico-geofísico a escala 1:50000 y búsquedas acompañantes en el municipio especial Isla de Juventud (CAME): La Habana, Guba, Oficina Nacional de Recursos Minerales (reporte técnico), 410 p. Bralower, T.J., Iturralde-Vinent, M.A., 1997, Micropaleontological dating of the collision between the North American Plate and the Greater Antilles Arc in western Cuba: Palaios, 12, 133-150.

Bratchell, N., 1989, Cluster analysis: Chemometrics and Intelligent Laboratory Systems 6, 105125.

Cobiella-Reguera, J.L., 1996, El magmatismo jurásico (Calloviano-Oxfordiano?) de Cuba occidental: ambiente de formación e implicaciones regionales: Revista de la Asociación Geológica Argentina, 51, 15-28.

Cobiella-Reguera, J.L., 2000, Jurassic and Cretaceous Geological History of Cuba: International Geology Review, 12, 595-616.

Cobiella-Reguera, J.L., Oloriz, F., 2009, Oxfordian-Berriasian stratigraphy of the North American paleomargin in the western Cuba: Constraints for the geological history of the proto-Caribbean and the early Gulf of Mexico, en Bartolini, C., Román-Ramos, 
J.R. (eds.), Petroleum systems in the southern Gulf of Mexico: Massachusetts, American Association of Petroleum Geologists Memoir 90 (Special Publications), 421-451.

Cruz-Gámez, E.M., Maresch, W.M., Cáceres, D., Balcázar, N., Martín, K., 2003, La Faja Cangre y sus rasgos metamórficos, Pinar del Río, Cuba, en Memorias del V Congreso de Geología y Minería: La Habana, Cuba, Sociedad Cubana de Geología, 11-18.

Cruz-Gámez, E.M., Maresch, W.V., Cáceres, D., Balcázar, N., 2007, Significado de las paragénesis de anfíboles en metagabros relacionados con secuencias de margen continental en el NW de Cuba: Revista Mexicana de Ciencias Geológicas, 24, 318327.

Despaigne-Díaz, A.I, 2009, Estructura y metamorfismo del área La Sierrita, macizo Escambray, Guba Central, Universidad de Pinar del Río, Tesis Doctoral, 101 p.

Despaigne-Díaz, A.I., García-Casco, A., CáceresGovea, D., Jourdan, F., Wilde, S.A., MillánTrujillo, G., 2016, Twenty-five millions years of subduction-accretion-exhumation history in the northwestern Caribbean: The Trinidad dome, Escambray complex, Central Cuba: American Journal of Sciences, 316 (3), 203240.

Dostal, J., Dupuy, G., 1984, Geochemistry of the North Mountain basalts (Nova Scotia, Canada): Chemical Geology, 45, 245-261.

Dublan, L., Alvarez, H., Mlcoch, B., Molak, B., Vázquez, C., de los Santos, E., Soucek, J., Pérez, M., Mihailova, A., Bernal, L., Zoubek , J., Ordoñez, M., Lavandero, R., Lledíaz, P., Morousek, J., Svetska, J., Mañour, J., Marshall, W., Pérez Conde, R., González, E., Rodríguez, R., 1986, Informe final al levantamiento Geológico y Evaluación de los minerales útiles a escala 1:50000 del Polígono CAME-1 (Zona centro): La Habana, Cuba, Oficina Nacional de Recursos Minerales (reporte técnico), $310 \mathrm{p}$.

Eguipko, O., Garapko, I., Sukar, K., Saunders, E., 1975, Zonación metamórfica y otros aspectos de la Isla de Pinos: Revista Minería y Geología, 1, 4-10.

Floyd, P.A., 1991, Oceanic basalts: New York, Springer Science + Business Media, LLC, $455 \mathrm{p}$.

Furrazola-Bermúdez, G., 1997, Sistema Jurásico, en Furrazola-Bermúdez, G., Núñez, K.E. (eds.), Estudios sobre Geología de Cuba: La Habana, Cuba, Centro Nacional de Información Geológica, Instituto de Geología y Paleontología, 75-96.

García-Casco, A., Torres-Roldán, R.L., Millán, G., Monié, P., Haissen, F., 2001, High-grade metamorphism and hydrous melting of metapelites in the Pinos terrane (W Cuba): Evidence for crustal thickening and extension in the northern Caribbean collisional belt: Journal of Metamorphic Geology, 19, 699715.

García-Casco, A., Torres-Roldán, R.L., IturraldeVinent, M., Millán-Trujillo, G., NúñezCambra, K., Lázaro, C., Rodríguez Vega, A., 2006, High-pressure metamorphism of ophiolites in Cuba: Geologica Acta, 4 (1-2), 63-88.

García-Casco, A., Iturralde-Vinent, M., Pindell, J., 2008, Latest Cretaceous collision/ accretion between the Caribbean Plate and Caribeana: Origin of metamorphic terranes in the Greater Antilles: International Geology Review, 50, 781-809.

Giunta, G., Beccaluva, L., Siena, F., 2006, Caribbean Plate margin evolution: constraints and current problems: Geologica Acta, 4, 1-2, 265-277.

González, R., 2013, Nuevos criterios acerca de la estratigrafía de la parte superior del corte geológico del macizo metamórfico de la Isla de la Juventud, en Memorias del X Congreso Cubano de Geología: La Habana, Cuba, 
Resumen GEO2-P9, 10.

González, R., Meriño, M., 2005, Aplicaciones para la cerámica de la Anfibolita Loma Daguilla (Isla de la Juventud), en Memorias del IV Congreso de Geología: La Habana, Cuba, Sociedad Cubana de Geología, ISBN 959-7117-03-7.

Gottfried, D., Annell, C.S., Byerly, G.R., 1983, Geochemistry and tectonic significance of subsurface basalts from Charleston, South Carolina: Clubhouse crossroads test holes $=2$ and $=3$ (USA): US Geological Survey Professional Paper, 1313, A1-A19.

Grossman, J., Gottfried D., Froelich A.J., 1991, Geochemical data for Jurassic diabase associated with early Mesozoic basins in the Eastern United States: U.S., Geology Survey, Open File Report, 91-322-J.

Haczewski, G., 1976, Sedimentological reconnaissance of the San Cayetano Formation: An accumulative continental margin in the Jurassic of Western Cuba: Acta Geologica Polonica, 26, 331-353.

Haskin, L.A., Haskin, M.A., Frey, F.A., Wilderman, T.R., 1968, Relative and absolute terrestrial abundances of the rare-earths, en Ahrens, L.H. (ed.), Origin and distribution of the elements: Londres, Gran Bretaña, Pergamon Press, 889-912.

Heatherington, A.L., Mueller, P.A., 1999, Lithospheric sources of North Florida, U.S.A. tholeiites and implications for the origin of the Suwannee terrane: Lithos, 46, 215-233.

Hutson, F. Mann, P., Renne, P., 1998, ${ }^{40} \mathrm{Ar}-{ }^{39} \mathrm{Ar}$ dating of single muscovite grains in Jurassic siliciclastic rocks (San Cayetano Formation): Constraints on the paleoposition of western Cuba: Geology, 26 (1), 83-86.

Iturralde-Vinent, M., 1988a, Las ofiolitas y el magmatismo de margen pasivo en la estructura geológica de Cuba: Boletín de Geociencias, Universidad de Pinar del Río, 3, 40-53.
Iturralde-Vinent, M., 1988b, Consideraciones generales sobre el magmatismo de margen continental de Cuba: Revista Tecnológica, 18, 17-24.

Iturralde-Vinent, M., 1994, Cuban Geology: a new plate-tectonic synthesis: Journal of Petroleum Geology, 17, 39-70.

Iturralde-Vinent, M., 1996, Magmatismo de Margen Continental de Cuba, en IturraldeVinent, M. (ed.), Cuban Ophiolites and Volcanic Arcs: IUGS/UNESCO Project 364, 121-130.

Iturralde-Vinent, M., 1998, Sinopsis de la Constitución Geológica de Cuba: Acta Geológica Hispánica, 33, 9-56.

Iturralde-Vinent, M., 2012, Geología de los Terrenos Metamórficos, Compendio de Geología de Cuba y del Caribe, Segunda Edición (DVD-ROM): La Habana, Cuba, en Iturralde-Vinent, Editorial CITMATEL.

Iturralde-Vinent, M., Marí, T., 1988, Toleitas del Tithoniano de la Sierra de Camaján. Camaguey: Posible datación de la corteza oceánica: Revista Tecnológica, XVIII, 2532.

Iturralde-Vinent, M., Pszczolkowski, A., 2012, Geología del Terreno Guaniguanico Compendio de Geología de Cuba y del Caribe, Segunda Edición (DVD-ROM): La Habana, Cuba, en Iturralde-Vinent, Editorial CITMATEL.

Jochum, K.P., Verma, S.P., 1996, Extreme enrichment of $\mathrm{Sb}, \mathrm{Tl}$ and other trace elements in altered MORB: Chemical Geology, 130, 289-299.

Kantchev, I.L., Boyanov, Y., Popov, N., Cabrera, R., Goranov, A.L., Iolkicev, N., Kanazirski, M., Stancheva, M., 1978, Geología de la provincia de Las Villas. Resultados del levantamiento geológico a escala 1:250000: La Habana, Cuba, Oficina Nacional de Recursos Minerales (reporte técnico), 290 p.

Kerr, A.C., Iturralde-Vinent, M.A., Saunders, A.D., Babbs, T.L., Tarney, J., 1999, A new 
plate tectonic model of the Caribbean: Implications from a geochemical reconnaissance of Cuba Mesozoic volcanic rocks: Geological Society of American Bulletin, 111, 1581-1599.

Linares, E., 1997, Magmatismo Jurásico, en Furrazola-Bermúdez, G., Núñez, K.E. (eds.), Estudios sobre Geología de Cuba: La Habana, Cuba, Centro Nacional de Información Geológica, Instituto de Geología y Paleontología, 289-292.

Martínez, D., Cofiño, C, Simon, A., 1987, Consideraciones acerca de las manifestaciones minerales relacionadas con los depósitos pertenecientes a la Formación Arroyo Cangre: Boletín de Geociencias, Pinar del Río, 2, 27-43.

Martínez, D., Fernández de Lara, R., 1988, Informe de los trabajos del levantamiento geológico y búsqueda a escala 1:50000 de la parte central de la provincia de Pinar del Río: Pinar del Río, Guba, Oficina Nacional de Recursos Minerales (reporte técnico), 285 p.

Martínez, D., Fernández de Lara, R., Pelaez, R., Vázquez, M., Barrios, E., Valido, A., Reinoso, R., Chang, J.C., Fernández, O., Denis, R., Gómez, L., García, D., Gil, S., Pérez, D.H., Reyes, R., Valdivia, M., Núñez, R., Pérez, R., Diz Langs, J., 1991, Informe de los trabajos del levantamiento geológico y prospección preliminar a escala 1:50000 Pinar-Habana: Pinar del Río, Cuba, Oficina Nacional de Recursos Minerales (reporte técnico), $330 \mathrm{p}$.

Marzoli, A., Renne, P.R., Piccirillo, E.M., Ernesto, M., Bellieni, G., De Min, A., 1999, Extensive 200-Million-Year-Old Continental Flood Basalts of the Central Atlantic Magmatic Province: Science, 284, 616-618.

McHone, J.G., 2000, Non plume magmatism and rifting during the opening of the Central Atlantic Ocean: Tectonophysics, 316, $287-$ 296.
Merle, R., Marzoli, A., Bertrand, H., Reisberg, L., Verati, C., Zimmermann, C., Chiaradia, M., Bellieni, G., Ernesto, M., 2011, ${ }^{40} \mathrm{Ar} /{ }^{39} \mathrm{Ar}$ ages and $\mathrm{Sr}-\mathrm{Nd}-\mathrm{Pb}-\mathrm{Os}$ geochemistry of CAMP tholeiites from Western Maranhão basin (NE Brazil): Lithos, 122, 137-151.

Millán, G., 1972, El metamorfismo y mesodeformaciones de la unidad tectónica más suroriental de Sierra de los Órganos: Academia de Ciencias de Cuba, Actas del Instituto de Geología, 2, 33-35.

Millán, G., 1975, El complejo cristalino mesozoico de la Isla de Pinos y su metamorfismo: Serie Geológica 23, 1-16.

Millán, G., 1981, Geología del macizo Isla de la Juventud: Revista Ciencias de la Tierra y el Espacio, 3, 3-22.

Millán, G., 1987, La asociación glaucofanapumpellita en metagabroides de la faja metamórfica Cangre: Boletín de Geociencias, 3, 35-36.

Millán, G., 1992, Posición estratigráfica de las metamorfitas Cubanas: Revista Minería y Geología, 2(2), 3-8.

Millán, G., 1995, Principales rasgos de la zonación estructuro-metamórfica del macizo Escambray: La Habana, Cuba, Resúmenes del X Forum de Ciencia y Técnica, 24-25.

Millán, G., 1997a, Posición estratigráfica de las metamorfitas cubanas, en FurrazolaBermúdez, G., Núñez, K.E. (eds.), Estudios sobre Geología de Cuba: La Habana, Cuba, Centro Nacional de Información Geológica, Instituto de Geología y Paleontología, 251258.

Millán, G., 1997b, Geología del macizo metamórfico Isla de la Juventud, en FurrazolaBermúdez, G., Núñez, K.E. (eds.), Estudios sobre Geología de Cuba: La Habana, Cuba, Centro Nacional de Información Geológica, Instituto de Geología y Paleontología, 259270.

Millán, G., 1997c, Geología del macizo metamórfico Escambray, en Furrazola- 
Bermúdez, G., Núñez, K.E. (eds.), Estudios sobre Geología de Cuba: La Habana, Cuba, Centro Nacional de Información Geológica, Instituto de Geología y Paleontología, 271288.

Millán, G., Álvarez-Sánchez, H., 1992, Geología del área de La Sierrita, parte occidental de la cúpula de Trinidad: La Habana, Cuba, Oficina Nacional de Recursos Minerales (reporte técnico), $135 \mathrm{p}$.

Millán, G., Myczyñski, R., 1979, Jurassic Ammonite fauna and age of metamorphic sequences of Escambray: Bulletin of Polish Academy of Sciences, 27, 37-47.

Millán, G., Somin, M.L., 1985a, Nuevos aspectos sobre la estratigrafía del macizo metamórfico Escambray: La Habana, Cuba, Instituto de Geología y Paleontología, Reporte de Investigación, 2, $42 \mathrm{p}$.

Millán, G., Somin, M.L., 1985b, Contribución al conocimiento geológico de las metamorfitas del Escambray y el Purial: La Habana, Cuba, Instituto de Geología y Paleontología, Reporte de Investigación, 2, 74 p.

Mottana, A, Carswell, D.A., Chopin, C., Oberhinsli, R., 1990, Eclogite facies mineral parageneses, en Carswell, D.A. (ed.), Eclogite facies rocks: Blackie, Glasgow and London, 14-52.

Nakamura, N., 1974, Determination of REE, Ba, $\mathrm{Mg}, \mathrm{Na}$ and $\mathrm{K}$ in carbonaceous and ordinary chondrites: Geochimica et Cosmochimica Acta 38, 757-775.

Pearce, J.A., 1982, Trace element characteristics of lavas from destructive plate boundaries, en Thorpe, R.S. (ed.), Andesites: Chichester, John Wiley \& Sons, 525-548.

Pearce, J.A., 1996, A user's guide to basalt discrimination diagrams: Geological Association of Canada Special Publication, $12,79-113$.

Pearce, J.A., 2008, Geochemical fingerprinting of oceanic basalts with applications to ophiolite classification and the search for Archean oceanic crust: Lithos 100, 14-48.

Pearce, J.A., 2014, Immobile Element Fingerprinting of Ophiolites: Elements, 10, 101-108.

Pegram, W.J., 1990, Development of continental lithospheric mantle as reflected in the chemistry of the Mesozoic Appalachian Tholeiites, U.S.A: Earth and Planetary Sciencie Letters, 97, 316-331.

Pindell, J., Kennan, L., 2009, Tectonic evolution of the Gulf of Mexico, Caribbean and northern South America in the mantle reference frame: an update: Geological Society of London, Special Publications, $328,1-55$.

Piotrowski, J., 1977, First manifestations of volcanism in the Cuban geosyncline: Académie Polonaise des Sciences Bulletin, Série des Sciences de la Terre, 24, 227-234.

Piotrowski, J., 1987, Primeras manifestaciones de vulcanismo en el Geosinclinal Cubano, en Pszczolkowski, A., Pistrowska, K., Piotroswski, J., De la Torre, A., Myczynski, R., Haczewski, G. (eds.), Contribución a la Geología de Pinar del Río: La Habana, Cuba, Editorial Científico-Técnica, 163169.

Plank, T., Langmuir, G.H., 1998, The chemical composition of subducting sediment and its consequences for the crust and mantle: Chemical. Geology, 145, 325-394

Pszczolkowski, A., 1978, Geosynclinal sequences on the Cordillera de Guaniguanico in western Cuba; their lithostratigraphy facies development and paleogeography: Acta Geologica Polonica, 28, 1-96.

Pszczolkowski, A., 1987, Secuencias miogeosinclinales de la Cordillera de Guaniguanico. Litoestratigrafia, desarrollo de facies y paleogeografía, en Pszczolkowski, A., Pistrowska, K., Piotroswski, J., De la Torre, A., Myczynski, R., Haczewski (eds.), Contribución a la Geología de Pinar del Río: La Habana, Cuba, Editorial Científico- 
Técnica, 5-84.

Pszczolkowski, A., 1989, La edad y posición de la secuencia vulcanógena-sedimentaria (Formación El Sábalo), en la estructura geológica de la Sierra del Rosario (Cuba Occidental), en Resúmenes del Primer Congreso Cubano de Geología: La Habana, Cuba, Sociedad Cubana de Geología, 66.

Pszczolkowski, A., 1999, The exposed Passive Margin of North America in Western Cuba, en Mann, P. (ed.), Caribbean Basins. Sedimentary Basins of the World, 4: Amsterdam, Holanda, Elsevier Science B.V., 93-121.

Pszczolkowski, A., Albear, J., 1983, La secuencia vulcanógeno sedimentaria de la Sierra del Rosario, provincia de Pinar del Río: Revista Ciencias de la Tierra y del Espacio, 6, 41-52. Pszczolkowski, A., Myczynski, R., 2003, Stratigraphic constraints on the Late JurassicCretaceous paleotectonic interpretations of the Placetas Belt in Cuba, en Bartolini, G., Buffler, R.T., Blickwede, J. (eds.), The Circum-Gulf of Mexico and the Caribbean: Hydrocarbon habitats, basin formation, and plate tectonics: Texas, American Association of Petroleum Geologists Memoir 79 (Special Publications), 551-588.

Rojas-Agramonte, Y., Kroener, A., Pindell, J., Garcia-Casco, A., Garcia-Delgado, D., Liu, D., Wang, Y., 2008, Detrital zircon geochronology of Jurassic Sandstones of Western Cuba (San Cayetano Formation): implications for the Jurassic paleogeography on the NW proto-Caribbean: Americam Journal Science, 308, 639-656.

Rollinson, H.R., 1993, Using geochemical data: evaluation, presentation, interpretation: Essex, Logman Publishers, 352 p.

Schneider, J., Bosch, D., Monie, P., Guillot, S., Garcia-Casco, A., Lardeaux, J.M., TorresRolda, R.L., Millán, G., 2004, Origin and evolution of the Escambray Massif (Central Cuba): an example of HP/LT rocks exhumed during intraoceanic subduction: Journal of Metamorphic Geology, 22, 227-247.

Segura-Soto, R., Millán, E., Fernández, J., 1985, Complejos litológicos del extremo noroccidental de Cuba y sus implicaciones estratigráficas de acuerdo con los datos de las perforaciones profundas: Revista Tecnológica, 15, 32-26.

Shein, V.S., Kleschov, K.A., 1985, Mapa tectónico de Cuba: Escala 1:500 000: Serie Geológica, 1, 37-40.

Somin, M.L., Millán, G., 1977, Sobre la edad de las rocas metamórficas cubanas: La Habana, Cuba, Instituto de Geología y Paleontología, Informe Científico-Técnico 2, 1-11.

Somin, M.L., Millán, G., 1981, Geología de los macizos metamórficos de Cuba (en ruso): Moscú, URSS, Editorial Nauka, 219 p.

Stanek, K.P., Maresch, W.V., Grafe, F., Grevel, CH., Baumann, A., 2006, Structure, tectonics and metamorphic of the Sancti Spiritus Dome (Eastern Escambray Massif, Central Guba): Geologica Acta, 4 (1-2), 151170.

Stanik, E., Mañour,J., Ching, R., 1981, Informe de los levantamientos geológicos, geoquímicos y trabajos geofísicos realizados en la parte sur de Cuba central en las provincias Cienfuegos, Sancti Spíritus y Villa Clara: La Habana, Cuba, Oficina Nacional de Recursos Minerales (reporte técnico), 345 p. Staudigel, H., Plank, T., White, B., Schmincke, H.U., 1996, Geochemical fluxes during seafloor alteration of the upper oceanic crust: DSDP sites 417-418, en Bebout, G.E., Scholl, D.W., Kirby, S.H., Platt, J.P. (eds), Subduction top to bottom. Geophysical Monograph: Washington, D.C., American Geophysical Union, 96, 19-38.

Torres-Roldán, R.L., García Casco, A, García Sánchez, P.A., 2000, C.Space: An integrated workplace for the graphical and algebraic analysis of phase assemblages on 32bit Wintel platforms: Computers and 
Geosciences 26, 779-793.

Velasco-Tapia, F., 2014, Multivariate analysis, mass balance techniques, and statistical tests as tools in igneous petrology: Application to the Sierra de las Cruces Volcanic Range (Mexican Volcanic Belt): Scientific World Journal, 2014, ID 793236, 32 p.

Verma, S.P., Guevara, M., Agrawal, S., 2006, Discriminating four tectonic settings: Five new geochemical diagrams for basic and ultrabasic volcanic rocks based on $\log -$ ratio transformation of major-element data: Journal of Earth System Sciences 115, 485528.
Walker, J.D., Geissman, J.W., Bowring, S.A., Babcock, L.E., 2013, The Geological Society of America Geologic Time Scale: Geological Society of America Bulletin, 125, 3-4 259-272

Ward, Jr., J.H., 1963, Hierarchical grouping to optimize an objective function: Journal of the American Statistical Association, 58, 236-244.

Winchester, J.A., Floyd, P.A., 1977, Geochemical discrimination of different magma series and their differentiation products using immobile elements: Chemical Geology, 20, 325-343. 